\title{
Effect of non-solvent additives on the morphology and separation performance of poly ( $m$-phenylene isophthalamide) (PMIA) hollow fiber nanofiltration membrane
}

\author{
Tao Wang ${ }^{\mathrm{a}}$, Changwei Zhao ${ }^{\mathrm{a}, *}$, Pei $\mathrm{Li}^{\mathrm{b}}, \mathrm{Ye} \mathrm{Li}^{\mathrm{c}}$, Jun Wang ${ }^{\mathrm{a}}$ \\ a Research Center for Eco-Environmental Sciences, Chinese Academy of Sciences, Beijing 100085, China \\ b College of Materials Science and Engineering, Beijing University of Chemical Technology, No. 15 Beisanhuandong Road, Chaoyang District, Beijing 100029, China \\ c Beijing Drainage Group Co. Ltd, Beijing 100176, China
}

\section{H I G H L I G H T S}

- PMIA hollow fiber NF membranes were fabricated.

- Effects of non-solvent additives on the morphology and separation performance were studied.

- High content of non-solvent additives resulted in narrow pore size, pore size distribution and high rejection.

\section{A R T I C L E I N F O}

\section{Article history:}

Received 12 January 2015

Received in revised form 10 March 2015

Accepted 11 March 2015

Available online 18 March 2015

\section{Keywords:}

PMIA

Nanofiltration

Hollow fiber

Non-solvent additive

Morphology

Separation performance

\begin{abstract}
A B S T R A C T
Newly designed poly ( $m$-phenylene isophthalamide) (PMIA) hollow fiber nanofiltration membranes were fabricated containing non-solvent additives, i.e., lithium chloride ( $\mathrm{LiCl}$ ), acetone and PVP by dry-jet wet spinning technology. The effects of non-solvent additives on the morphology and separation performance were investigated. The addition of non-solvent additives in the dopes enhanced the viscosity significantly. The membrane crosssections were monitored by scanning electron microscopy (SEM). The results indicated that by increasing the concentration of non-solvent additives, the morphologies changed from finger-like to sponge-like, and the outer skin-layer thickness was slightly increased. The rejections to various salts and pure water permeability (PWP) of these membranes were determined. The mean pore size and molecular weight cut-off (MWCO) were estimated using the solute rejection method. The results showed that the salt rejection of the membranes decreased in the order of $R\left(\mathrm{Na}_{2} \mathrm{SO}_{4}\right)>R\left(\mathrm{MgSO}_{4}\right)>R(\mathrm{NaCl})>R\left(\mathrm{MgCl}_{2}\right)$, and as the concentrations of non-solvent additives increased, the PWPs, mean pore sizes and MWCOs of the PMIA membranes all decreased. The atomic force microscope (AFM) experiments demonstrated that a smooth membrane surface was formed by adding non-solvent additives. Furthermore, the stress values at break, the elongation at break and the elastic modulus of the fibers increased as non-solvent additive contents increased.
\end{abstract}

C 2015 Elsevier B.V. All rights reserved.

\section{Introduction}

Nanofiltration (NF) membrane was firstly introduced in the late 1980s with separation characteristic between ultrafiltration (UF) and reverse osmosis (RO) membrane. The pore size in NF membrane is nominally $1.0 \mathrm{~nm}$ and its MWCO (molecular weight of solute that is $90 \%$ rejected by the membrane) ranges from 200 to 1000 Da [1-6]. The separation mechanism of NF membrane involves a combination of steric (size exclusion) effect and electric (Donnan exclusion) effect. In the last few decades NF membrane technique has gained significant attention and be applied successfully in many fields such as drinking

\footnotetext{
* Corresponding author.

E-mail address: zhaocw@rcees.ac.cn (C. Zhao).
}

water [7-13], dye wastewater [14-19], food industry [20,21] and other industrial applications [22-29].

At present, most of commercial NF membranes are thin-film composite (TFC) membranes which are made by spreading a thin selective layer on the top of porous asymmetric substrate [30]. The thin layer is typically fabricated using interfacial polymerization (IP), in-situ polymerization, chemical modification or surface coating et al. Although these techniques are proved to be effective, their fabrication processes are complicated. On the contrary, fabrication of a wholly integrally asymmetric hollow fiber membrane with an ultra-thin selective layer and highly porous substrate by the Loeb-Sourirajan phase-inversion technology can avoid the sophisticated and time consuming procedure to form the thin layer of the composite membrane. Today, most commercialized NF membranes are still limited to flat-sheet, spiral wound 
or tubular configurations [31,32]. Compared with them, hollow fiber configuration has some intrinsic advantages such as higher packing density, smaller foot print, relatively larger membrane surface area per unit volume, and lower operation cost $[33,34]$. Therefore, many researchers from both industry and academia focus on developing hollow fiber NF membranes.

For instance, Wang and Chung used polybenzimidazole (PBI) to fabricate hollow fiber NF membranes through the phase-inversion method [35]. These PBI membranes exhibited outstanding mechanical strength and good chemical stability with a mean pore size of $0.348 \mathrm{~nm}$ and a pure water permeability (PWP) of $1.861 \mathrm{~L} /\left(\mathrm{m}^{2} \cdot \mathrm{h} \cdot \mathrm{bar}\right)$. Yang et al. developed the poly(phthalazinone ether sulfone ketone) (PPESK) hollow fiber NF membranes with a MWCO of approximately 600 Da [36]. They also fabricated a polypiperazine amide/PPESK hollow fiber composite NF membrane via interfacial polymerization of piperazine (PIP) in water with trimesoyl chloride (TMC) in hexane [37]. The resultant composite membrane showed a high rejection to $\mathrm{Na}_{2} \mathrm{SO}_{4}$ and a high water flux of $45 \mathrm{~L} /\left(\mathrm{m}^{2} \cdot \mathrm{h}\right)$ under $0.35 \mathrm{MPa}$. Bolong et al. developed a hollow fiber NF membrane using polymer blends which consisted of polyethersulfone and a charged surface modifying macromolecule [38]. The modified membrane possessed a mean pore size of $1.2 \mathrm{~nm}$. Sun et al. fabricated a dual-layer composite hollow fiber NF membrane by the simultaneous co-extrusion of polyamide-imide and cellulose acetate dopes [39]. The dual-layer NF hollow fiber membrane had a relatively high PWP of $11.93 \mathrm{~L} /\left(\mathrm{m}^{2} \cdot \mathrm{h} \cdot \mathrm{bar}\right)$, and a mean effective pore radius of $0.63 \mathrm{~nm}$. Yu et al. fabricated NF hollow fiber membranes from polypropylene (PP) hollow fiber microfiltration membranes through dipcoating sodium carboxymethyl cellulose $(\mathrm{CMCNa})$ on the outer surface of the membrane followed by cross-linking with $\mathrm{AlCl}_{3}$ and $\mathrm{FeCl}_{3}[40,41]$. The modified membrane had a MWCO of 760 Da and a high PWP of $10.8 \mathrm{~L} /\left(\mathrm{m}^{2} \cdot \mathrm{h} \cdot\right.$ bar $)$. Moreover, the rejection of Congo red and Methyl blue was higher than $99.8 \%$ and $99.6 \%$, respectively. He and coworkers developed a novel composite NF membrane by coating sulfonated poly (ether ether ketone) (SPEEK) on the polyethersulfone hollow fiber substrate [42]. The membrane exhibited a good retention of $97-100 \%$ to organic dyes.

Above all, many hollow fiber NF membranes with good separation performances have been developed. However, membrane materials, which are crucial for achieving better separation performance, excellent mechanical properties and good stabilities at harsh operation conditions, are still limited to CA, PPESK, PES, etc. PMIA whose chemical structure is shown in Fig. 1 has been widely used as a promising structural material because of its outstanding thermal resistivity $\left(\mathrm{T}_{\mathrm{g}}=270^{\circ} \mathrm{C}\right)$ and chemical stabilities that are attributed to its 3-D jungle-gym-type hydrogen bond network $[43,44]$. The good physiochemical properties
Table 1

Diffusivities and Stokes radii of neutral solutes in aqueous solutions (at $25^{\circ} \mathrm{C}$ ).

\begin{tabular}{llll}
\hline Solute & $\mathrm{M}_{\mathrm{W}}\left(\mathrm{g} \mathrm{mol}^{-1}\right)$ & $\mathrm{D}_{\mathrm{s}}\left(\times 10^{-9} \mathrm{~m}^{2} \mathrm{~s}^{-1}\right)$ & $r_{s}(\mathrm{~nm})$ \\
\hline Glucose & 180 & 0.67 & 0.365 \\
Saccharose & 342 & 0.52 & 0.471 \\
Raffinose & 504 & 0.42 & 0.584 \\
$\alpha$-Cyclodextrin & 972 & 0.35 & 0.701 \\
\hline
\end{tabular}

make PMIA a promising membrane material. Huang and Zhang have successfully fabricated the PMIA flat-sheet nanofiltration membranes which showed good separation performance in the dye purification and desalination processes [45]. Compared to their work, our PMIA nanofiltration membranes were in a hollow fiber form. Unlike flat sheet membrane which typically required a supporting layer such as a non-woven substrate used in Huang and Zhang's work, hollow fiber membrane has a self-supporting character. Hence, developing hollow fiber NF membranes gives an alternative (maybe more suitable) solution for future application of PMIA membranes. Moreover, formation of PMIA nanofiltration membrane is controlled by a number of variables including the dope composition and fabrication conditions. So it is important to understand the effects of the variables on the membrane structure and performance in order to have a proper control on the properties of the resultant membrane. In a previous relevant work, Huang and Zhang investigated the effects of additives on the separation performance of the PMIA flat sheet membrane for dye treatment. However, the effects of additives on membrane morphology were not addressed. To the best of our knowledge, no reports have discussed the effect of non-solvent additives on the morphology and performance of the PMIA hollow fiber nanofiltration membrane. Therefore, the purpose of this work is to explore suitable spinning parameters for developing PMIA hollow fiber NF membranes. In this study, the dope solutions, which consist of N,N-dimethylacetamide (DMAc) as a less volatile solvent, acetone as volatile non-solvent, lithium chloride ( $\mathrm{LiCl}$ ) as inorganic additive, and PVP as organic additive, were mixed to form homogeneous dope solutions, and the effects of these non-solvent additives on the membrane morphologies and separation performances were studied.

\section{Experimental}

\subsection{Materials}

PMIA was purchased from DuPont (USA) and was dried at $120{ }^{\circ} \mathrm{C}$ in vacuum for $24 \mathrm{~h}$ before use. N,N-dimethylacetamide (DMAc, $>99 \%$ ) was<smiles>CCC(=O)c1cccc(C(=O)Nc2cccc(N(C)C)c2)c1</smiles>

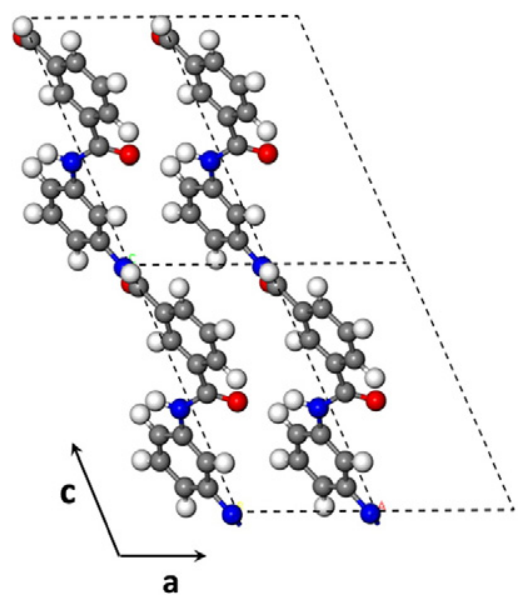

Fig. 1. Chemical structure and three-dimensional crystal structure of PMIA. 
Table 2

The compositions of the dope solutions.

\begin{tabular}{llllll}
\hline $\begin{array}{l}\text { Membrane } \\
\text { code }\end{array}$ & $\begin{array}{l}\text { PMIA } \\
\text { (wt.\%) }\end{array}$ & $\begin{array}{l}\text { DMAc } \\
\text { (wt.\%) }\end{array}$ & $\begin{array}{l}\text { LiCl } \\
\text { (wt.\%) }\end{array}$ & $\begin{array}{l}\text { Acetone } \\
\text { (wt.\%) }\end{array}$ & $\begin{array}{l}\text { PVP } \\
\text { (wt.\%) }\end{array}$ \\
\hline M1 & 19 & 78 & 3 & - & - \\
M2 & 19 & 76 & 5 & - & - \\
M3 & 19 & 74 & 7 & & - \\
M4 & 19 & 72 & 5 & 4 & - \\
M5 & 19 & 70 & 5 & 6 & - \\
M6 & 19 & 68 & 5 & 8 & - \\
M7 & 19 & 69.5 & 5 & 6 & 0.5 \\
M8 & 19 & 68.5 & 5 & 6 & 1.5 \\
M9 & 19 & 67 & 5 & 6 & 3.0 \\
\hline
\end{tabular}

obtained from Shanghai Jingwei Chemical Co., Ltd (China). LiCl (>95\%) and acetone (>99.5\%) were supplied by Tianjin Guangfu Research Institute of Fine Chemical Engineering (China). PVP K15 with an average molecular weight of $10 \mathrm{kDa}$ was gotten from Tokyo Chemical Industry Co., Ltd (Japan). Glucose, saccharose, raffinose, and $\alpha$-cyclodextrin were purchased from Sigma-Aldrich (USA) of which the molecular weights, diffusivities and Stokes radii were listed in Table 1 [46]. Sodium chloride $(\mathrm{NaCl})$, sodium sulfate $\left(\mathrm{Na}_{2} \mathrm{SO}_{4}\right)$, magnesium chloride $\left(\mathrm{MgCl}_{2}\right)$ and magnesium sulfate $\left(\mathrm{MgSO}_{4}\right)$ were purchased from Sinopharm Chemical Reagent Co., Ltd (China). All the chemicals were used without further purification.

\subsection{Fabrications of hollow fiber membranes and modules}

A DMAc and non-solvent additive mixture was first prepared in a 5 liter reaction tank and then a desired amount of dry PMIA was added in. The PMIA was dissolved in the solution at $85^{\circ} \mathrm{C}$ with agitation until a clear homogeneous polymer solution was obtained. After that, the polymer solution was cooled down to $50{ }^{\circ} \mathrm{C}$ and degassed for $48 \mathrm{~h}$ before hollow fiber spinning. Table 2 lists the compositions of all dope solutions.

Fig. 2 illustrates the diagram of hollow fiber spinning apparatus. The dope solution was first filtered and then coextruded with a bore fluid (water) through a spinneret to form a hollow fiber. The nascent fiber passed through an air gap, deionized water, and finally collected on a winder. Table 3 lists the detailed spinning conditions. After spinning, the fibers were rinsed in a circulating deionized water bath at $40{ }^{\circ} \mathrm{C}$ for $72 \mathrm{~h}$ to leach out the residual solvent. At last, the hollow fiber membranes was soaked in a $50 \mathrm{wt}$.\% glycerol aqueous solution for $48 \mathrm{~h}$ and followed by air-drying at room temperature.
Table 3

The spinning conditions and detailed parameters.

\begin{tabular}{ll}
\hline Spinning condition/process parameters & Value \\
\hline Dope solution temperature $\left({ }^{\circ} \mathrm{C}\right)$ & 50 \\
Spinneret dimension OD/ID $(\mathrm{mm} / \mathrm{mm})$ & $1.40 / 0.70$ \\
Spinneret temperature $\left({ }^{\circ} \mathrm{C}\right)$ & 50 \\
Bore fluid/external coagulant & Deionized water \\
Dope flow rate $(\mathrm{mL} / \mathrm{min})$ & 6.0 \\
Bore fluid flow rate $(\mathrm{mL} / \mathrm{min})$ & 3.0 \\
Air gap distance $(\mathrm{cm})$ & 20 \\
Bore liquid/external coagulant temperature $\left({ }^{\circ} \mathrm{C}\right)$ & $25 \pm 1$ \\
Take-up speed & Free fall \\
Room relative humidity $(\%)$ & $25 \pm 3$ \\
\hline
\end{tabular}

a Outer diameter/inner diameter.

Bundles of hollow fibers containing 8 fibers with about $22 \mathrm{~cm}$ in length were prepared. The shell sides of the two ends of each bundle were glued onto a nylon tube holder using a normal solidified epoxy resin. Afterwards, these modules were immersed into deionized water to leach out glycerol before test.

\subsection{Viscosity measurement}

The viscosity of the dope solutions was measured using a numerical display viscometer (CAP2000 + H, Brookfield Engineering Laboratories, Inc. USA). The experiments were carried out at $50{ }^{\circ} \mathrm{C}$ with the CAP-04 spindle at $200 \mathrm{rpm}$ and a shear rate of $667 \mathrm{~s}^{-1}$.

\subsection{PWP, mean effective pore size and pore size distribution determined by the solution transport method}

Fig. 3 shows a schematic diagram of a lab-scale circulating filtration unit. For each hollow fiber membrane, two modules were tested simultaneously to ensure good reproducibility. Since the outer surface of the hollow fiber was the selective layer, the feed solutions were pumped into the shell side, while the permeate solutions exited from the fiber lumen sides. A high flow rate of $1.50 \mathrm{~L} \cdot \mathrm{min}^{-1}$ of the feed solutions was applied to minimize the effect of concentration polarization $(\operatorname{Re}>4000)$. The hollow fiber membranes were conditioned at the pressure of $10 \mathrm{bar}$ for $24 \mathrm{~h}$. Then, the membrane samples were subjected to the pure water permeation test at 7 bar to measure the volumetric flow rate of water. The PWP was calculated as follows:

$P W P=\frac{Q}{\Delta P \times A}$

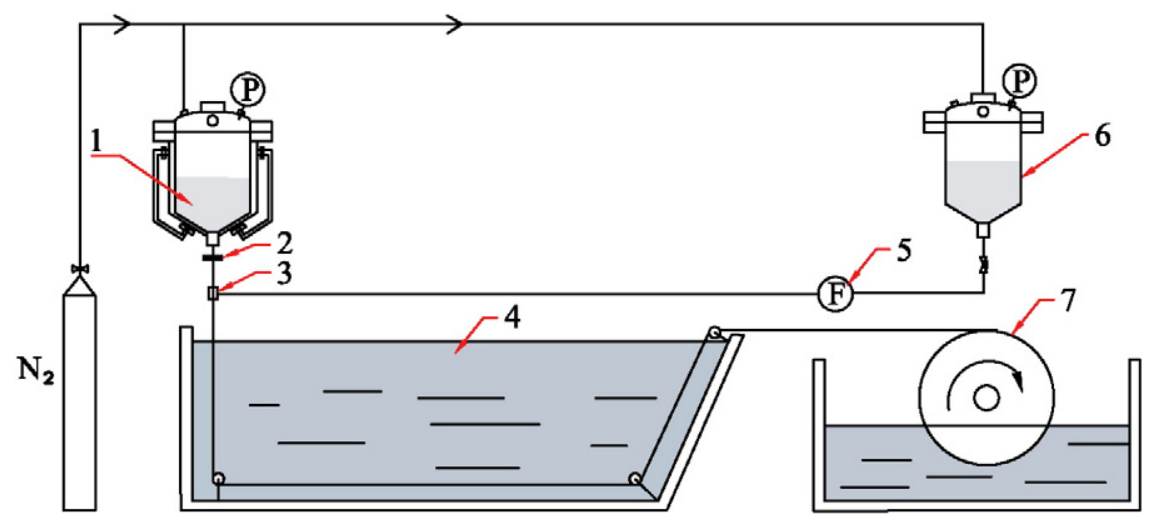

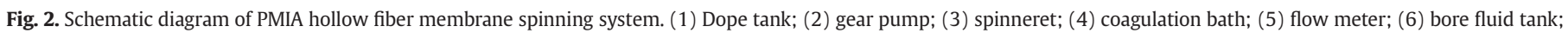
(7) take-up winder. 


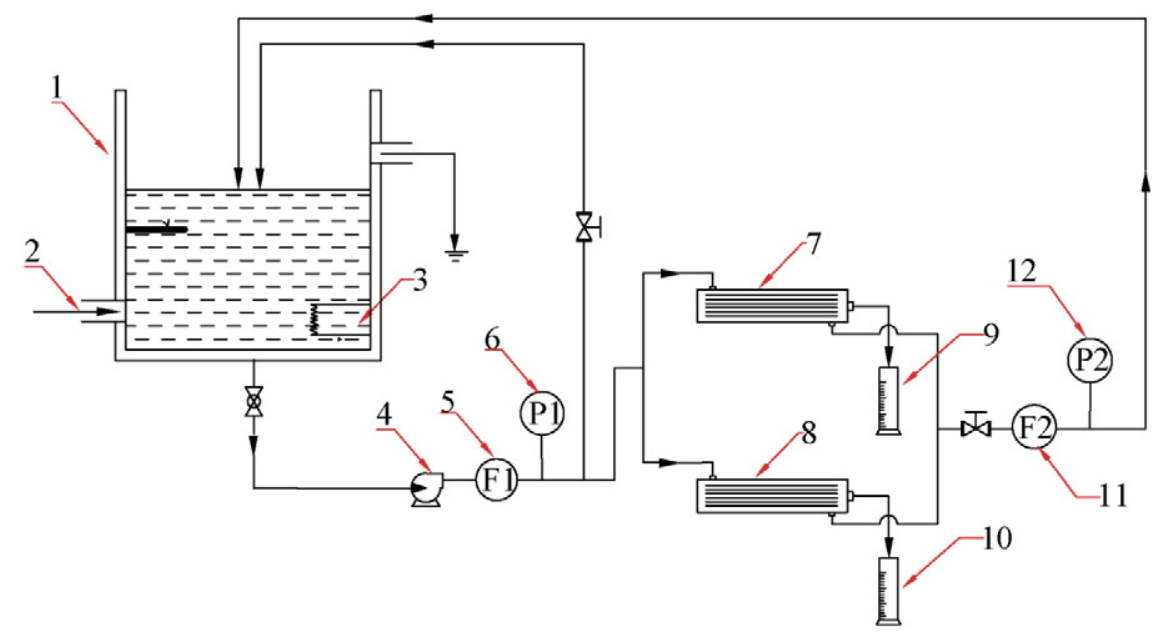

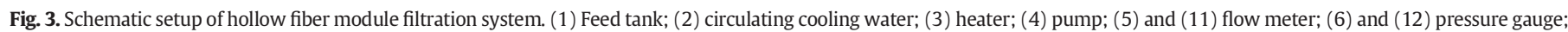
(7) and (8) hollow fiber membrane permeation cell; (9) and (10) permeate.

where $Q$ is the water permeation volumetric flow rate $\left(\mathrm{L} \cdot \mathrm{h}^{-1}\right), A$ is the effective filtration area $\left(\mathrm{m}^{2}\right)$, and $\Delta P$ is the transmembrane pressure drop (bar), respectively.

The membranes were then characterized by the solute transport method using various inorganic salts $\left(\mathrm{NaCl}, \mathrm{Na}_{2} \mathrm{SO}_{4}, \mathrm{MgCl}_{2}, \mathrm{MgSO}_{4}\right)$ and neutral organic solutes (glucose, saccharose, raffinose, $\alpha$-cyclodextrin) to obtain the separation performance, mean effective pore size and pore size distributions. The membrane solute rejection $R(\%)$ was estimated using Eq. (2):

$R(\%)=\left(1-\frac{c_{p}}{c_{f}}\right) \times 100$

where $C_{p}$ and $C_{f}$ represent the solute concentrations in the permeate and feed solutions, respectively.

The inorganic salt solutions with a concentration of $3.4 \mathrm{mM}$ were utilized to measure the salt rejections. The experimental system was operated for $24 \mathrm{~h}$ to reach the steady state. Then, the permeate samples were collected at different pressures. The salt concentrations of the permeate samples were determined using an electrical conductivity meter (DDSJ-308A, Shanghai Leica Instrument Works, China). The salt

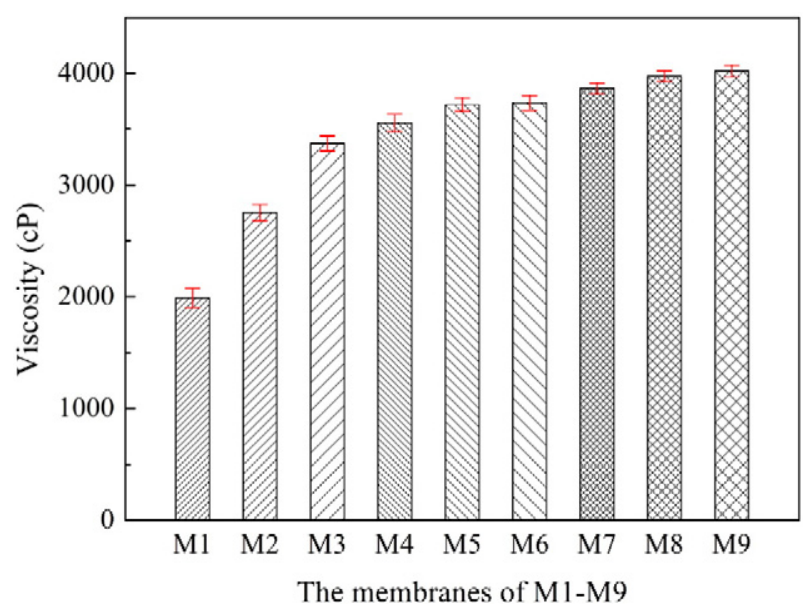

Fig. 4. The comparisons of viscosities of different polymer dope solutions. rejections were estimated using Eq. (2) with the experimentally determined salt concentration in the permeate sample and the designed salt concentration in the feed.

The 200 ppm neutral organic solute solutions were prepared to estimate the effective pore size and pore size distributions [47,48]. The operating procedures were similar to the salt rejection experiments. Concentrations of the neutral solutes in the feed and permeate solutions were obtained using a total organic carbon analyzer (Liquic TOC, Elementar, Germany). The solute rejection was expressed in Eq. (3) which correlated the solute rejection with a log-normal probability function of solute size.

$R_{T}=1-\frac{c_{p}}{c_{f}}=\frac{1}{\sqrt{2 \pi}} \int_{-\infty}^{y} e^{-\left(u^{2} / 2\right)} d u$

with

$y=\frac{\ln r_{s}-\ln \mu_{s}}{\ln \sigma_{g}}$

where $R_{T}$ is the solute rejection; $C_{p}$ and $C_{f}$ are the concentrations of the solute in the permeate and feed solutions, respectively; $r_{s}$ is the solute radius; $\mu_{s}$ is the geometric mean radius of solute at $R_{T}=50 \%$; and $\sigma_{g}$ is the geometric standard deviation about $\mu_{s}$, defined as the ratio of $r_{s}$ at $R_{T}=84.13 \%$ and $R_{T}=50 \%$. When the solute rejection of a membrane is plotted against solute radius on log-normal probability coordinates, a straight line is obtained:

$F\left(R_{T}\right)=A+B\left(\ln r_{s}\right)$

Ignoring the influences of the steric and hydrodynamic interaction between solute and pores on the solute rejection, the mean effective

Table 4

The solubility parameters of dope component and the solubility parameter distance.

\begin{tabular}{llcll}
\hline Dope component & $\delta_{d}\left(\mathrm{MPa}^{1 / 2}\right)$ & $\delta_{p}\left(\mathrm{MPa}^{1 / 2}\right)$ & $\delta_{h}\left(\mathrm{MPa}^{1 / 2}\right)$ & $R a^{\mathrm{a}}\left(\mathrm{MPa}^{1 / 2}\right)$ \\
\hline DMAc & 16.8 & 11.5 & 10.2 & - \\
PMIA & 17.71 & 5.88 & 7.24 & 6.61 \\
PVP & 16.06 & 12.13 & 8.75 & 2.17 \\
\hline
\end{tabular}

${ }^{\mathrm{a}} R a=\sqrt{4(\delta d 2-\delta d 1)^{2}+(\delta p 2-\delta p 1)^{2}+(\delta h 2-\delta h 1)^{2}} .$. 
pore radius $\left(\mu_{p}\right)$ and the geometric standard deviation $\left(\sigma_{p}\right)$ can be assumed to be the same as $\mu_{s}$ and $\sigma_{g}$, the pore size distribution of the NF membranes can be expressed as the following probability density function:

$\frac{\mathrm{d} R\left(d_{p}\right)}{\mathrm{d} d_{p}}=\frac{1}{\mathrm{~d}_{p} \ln \sigma_{p} \sqrt{2 \pi}} \exp \left[-\frac{\left(\ln d_{p}-\ln \mu_{p}\right)^{2}}{2\left(\ln \sigma_{p}\right)^{2}}\right]$

where $d_{p}$ is the effective pore radius of the NF membrane.

Therefore, measuring the rejections to neutral solutes with different molecular weights, the relationship between the Stokes radius and molecular weight $\left(\mathrm{M}_{\mathrm{W}}\right)$ of the known neutral solute can be obtained using the following equation:

$\log r_{s}=-1.32352+0.39521 \log M_{W}$

where $r_{s}$ is the corresponding Stokes radius of the neutral solutes with the unit of nm, and $M_{W}$ are the molecular weights of glucose, saccharose, raffinose, $\alpha$-cyclodextrin, with the unit of $\mathrm{g} / \mathrm{mol}$. Based on this equation, the radius of a given solute can be obtained and the MWCO, which is referred to as a molecular weight of a solute that $90 \%$ of it is retained by the membrane, is acquired.

\subsection{Characterization of membrane morphology}

The morphologies of the NF hollow fiber membranes were observed using a HITACHI SU8000 scanning electron microscope (SEM) (Hitachi
Ltd., Japan). The membrane samples were frozen in liquid nitrogen, fractured and then sputtered with platinum using a HITACHI E-1010 Ion Sputtering coater.

\subsection{Membrane surface analysis}

The membrane surface roughness was measured using a Multimode SPM equipped with a J-type piezoelectric scanner and a Nanoscope IIla controller (Digital Instruments, USA). The membrane surface images were obtained with a scan area of $5 \mu \mathrm{m} \times 5 \mu \mathrm{m}$. Roughness values were estimated from topography scans using the Nanoscope control software (Version 7.30).

\subsection{Characterization of membrane mechanical properties}

Mechanical properties of the hollow fiber membranes were measured using an Instron 5565-5kN tensile test machine (Instron Corporation, USA) at room temperature. The membrane sample was clamped at both ends and pulled in tension at a constant elongation velocity of $10 \mathrm{~mm} / \mathrm{min}$ with an initial length of $200 \mathrm{~mm}$, six specimens were tested for each sample.

\section{Results and discussions}

\subsection{Effect of the additives on the viscosity of the spinning dope solutions}

The presence of the additives in the polymer solution not only changes the thermodynamic state of the dope solution but also
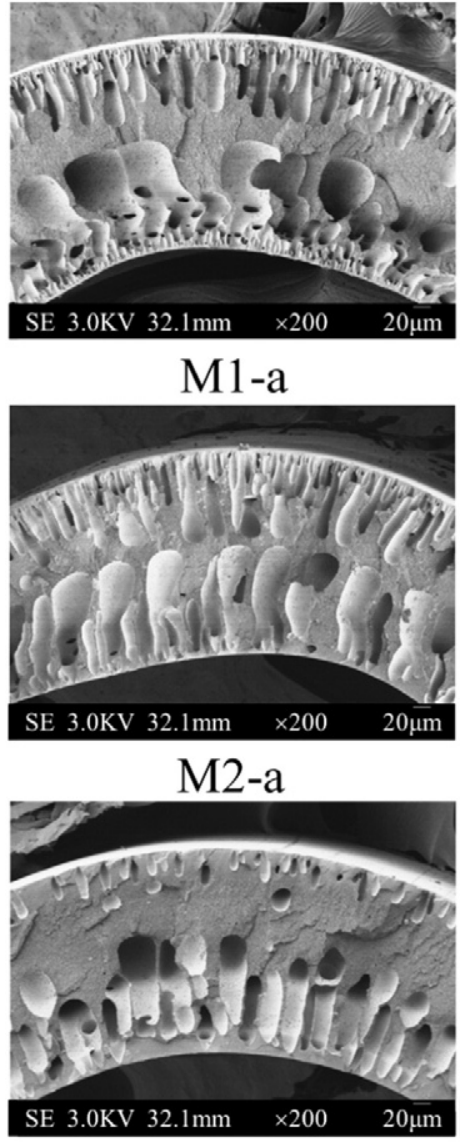

M3-a
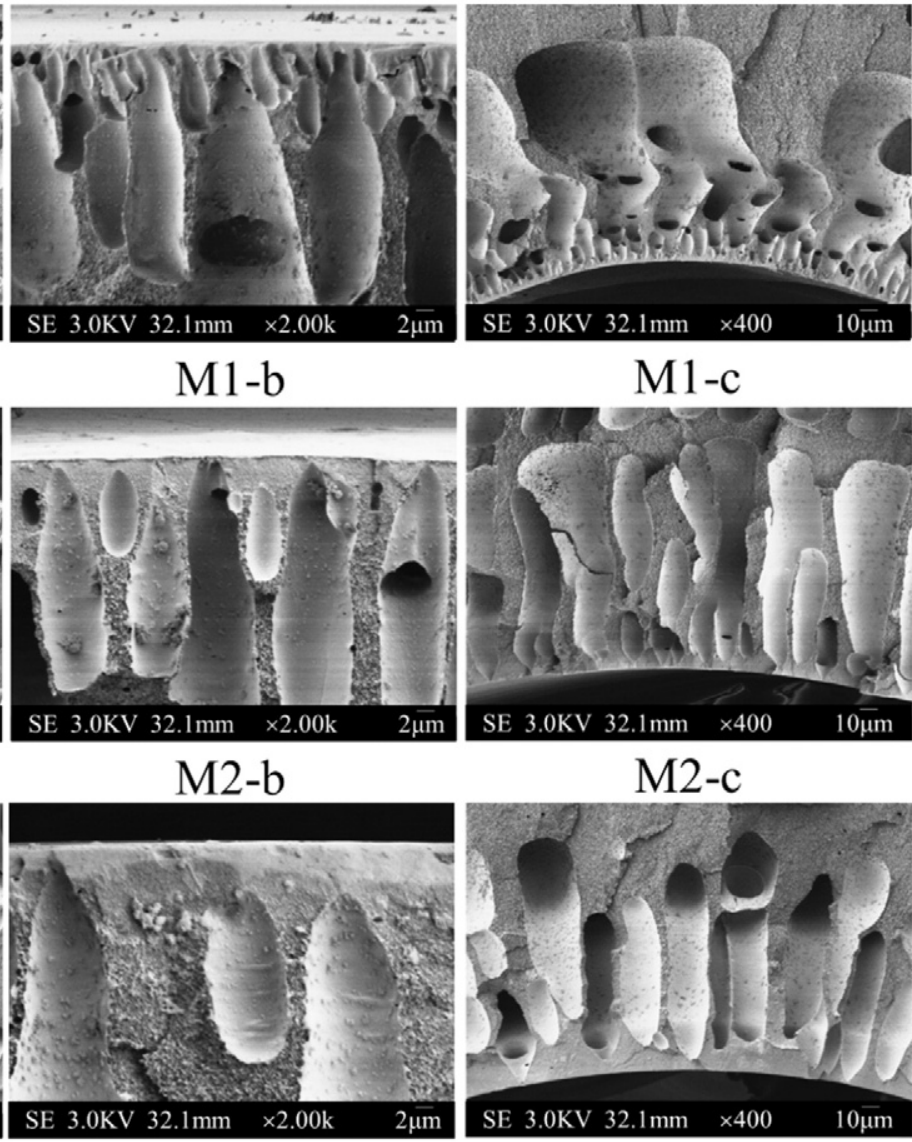

M3-b

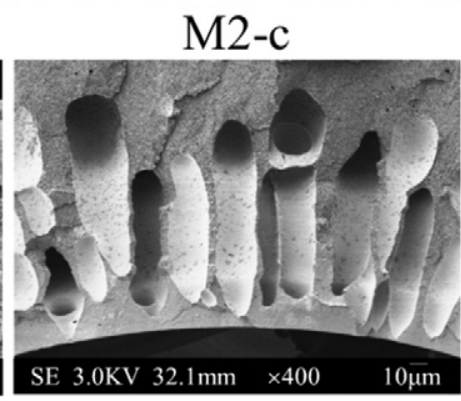

M3-c

Fig. 5. Cross-section morphology of hollow fiber membranes prepared with LiCl as additive: (a) cross section; (b) cross section near outer layer; (c) cross section near inner layer. 
influences the conformation and dynamics of the polymer [49]. Viscosity of the dope solution, as a key parameter to affect the membrane formation process, can influence the exchange rate of solvent/non-solvent, the phase separation speed and the gelation dynamics, and ultimately affects the structure and performance of the membrane. Therefore, tuning viscosity is likely to be a powerful tool for controlling the membrane morphology and separation performance.

Fig. 4 shows the viscosities of different dope solutions measured at $50{ }^{\circ} \mathrm{C}$ that is the dope temperature when spinning hollow fibers. As the concentration of $\mathrm{LiCl}$ increases from 3 to $7 \mathrm{wt} . \%$, the dope viscosities of M1, M2 and M3 increases from $1989 \mathrm{cP}$ to $3371 \mathrm{cP}$. It can be attributed to the complex formed between the carbonyl group of DMAc and $\mathrm{LiCl}$ via ion-dipole interaction [50].

Compared with the viscosity of dope solution M2, the introduction of acetone further increases the dope viscosity. It might be due to the interactions between the DMAc and acetone that increase the absolute viscosity of DMAc and lead to an increase in the viscosity of the dope solutions. Similar phenomenon was reported by Wang et al. [51], who studied the effects of different alcohols on the viscosities of PSF/NMP/alcohol systems. They claimed that a higher dope viscosity was correlated to a higher viscosity of the solvent/alcohol system. In addition, with the addition of acetone, the solvent power of DMAc is significantly reduced and the composition of polymer dope is closer to the binodal curve (precipitation point). The polymer chains tend to aggregate which enhances the dope viscosity.
Fig. 4 also shows that the viscosities of the dope solutions with PVP are higher than those of the dope solutions without it. Table 4 lists the Hansen solubility parameter [52] of DMAc, PMIA and PVP. The solubility distance (Ra) between PMIA and DMAc (6.61 MPa ${ }^{1 / 2}$ ) is higher than that between PVP and DMAc (2.17 $\left.\mathrm{MPa}^{1 / 2}\right)$. Hence, when PVP is added to a PMIA/DMAc solution, the higher affinity between PVP and DMAc molecules reduces the dissolving power of DMAc and enhances the PMIA-PMIA interaction. In this case, the PMIA chains may have more tightly coiled conformation and form aggregations in the dope solution that causes an increase in the viscosity [53].

\subsection{Effect of the additives on the membrane morphologies}

In general, the separation performance of membranes strongly depends on the surface, sub-layer morphology, and top layer thickness and compactness [54-56]. The resultant membrane morphology and structure can be modified by controlling the phase-inversion rate and rheology of the dope. Fig. 5 shows the morphologies of the hollow fiber membranes prepared from the dopes coded as M1, M2 and M3. It can be seen that all the membranes exhibit typical asymmetric structures. The membrane prepared from the $3 \mathrm{wt} . \% \mathrm{LiCl}$ dope shows many long and large finger-like macro-voids near the outer layer. When more $\mathrm{LiCl}$ is added into the dope solution, the number and size of finger-like macro-voids decrease significantly and the outer skin-layer thickness of the hollow fiber membranes slightly increased. As the
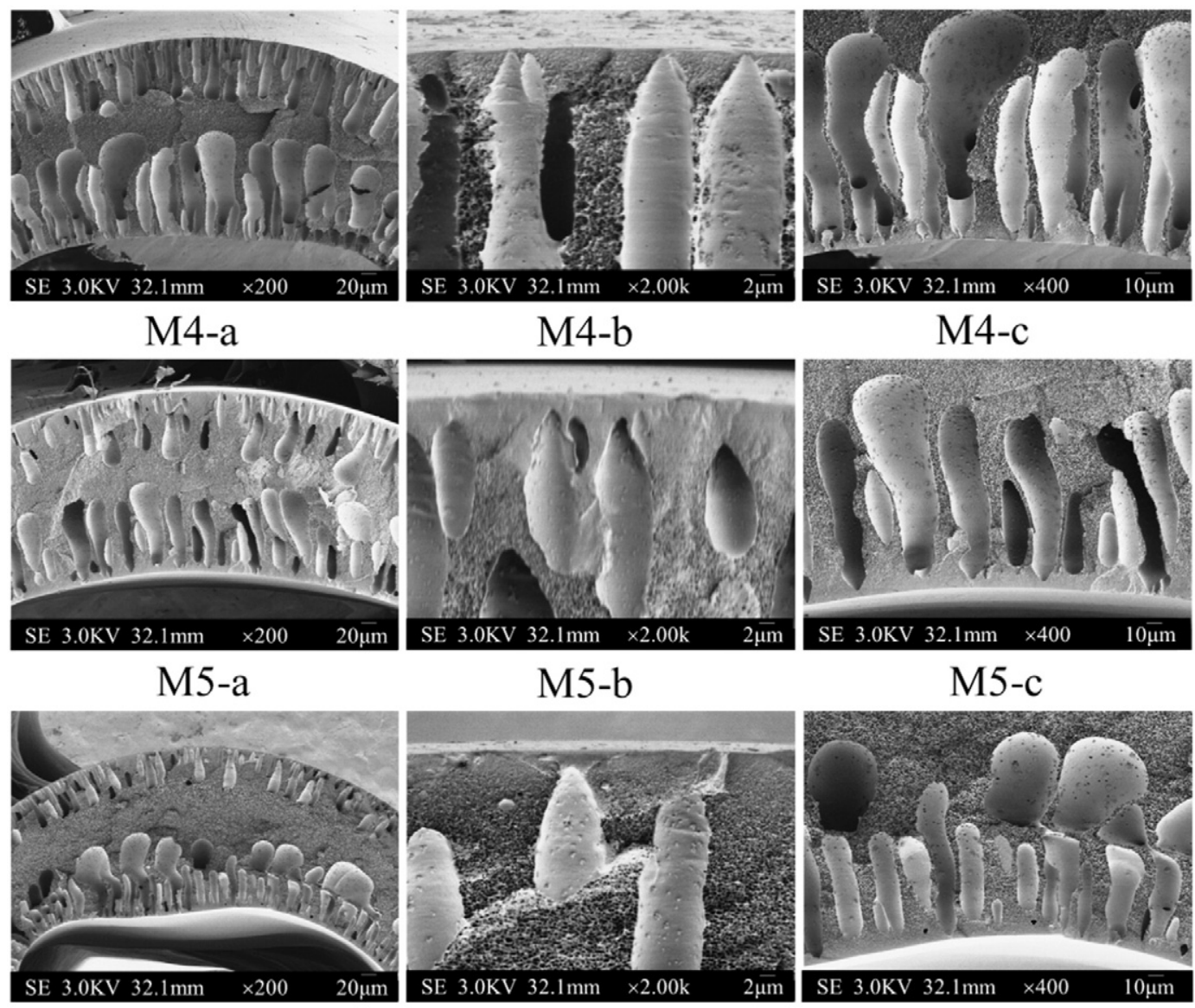

M6-a

M6-b

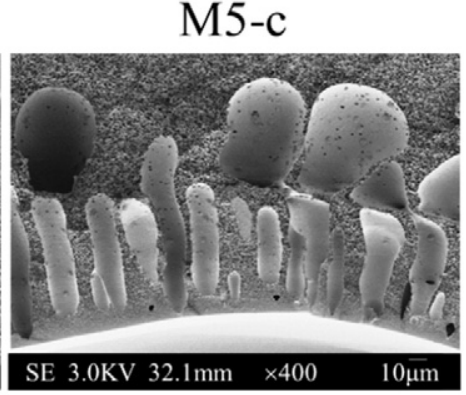

M6-c

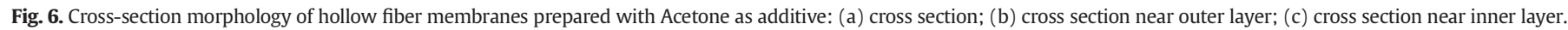



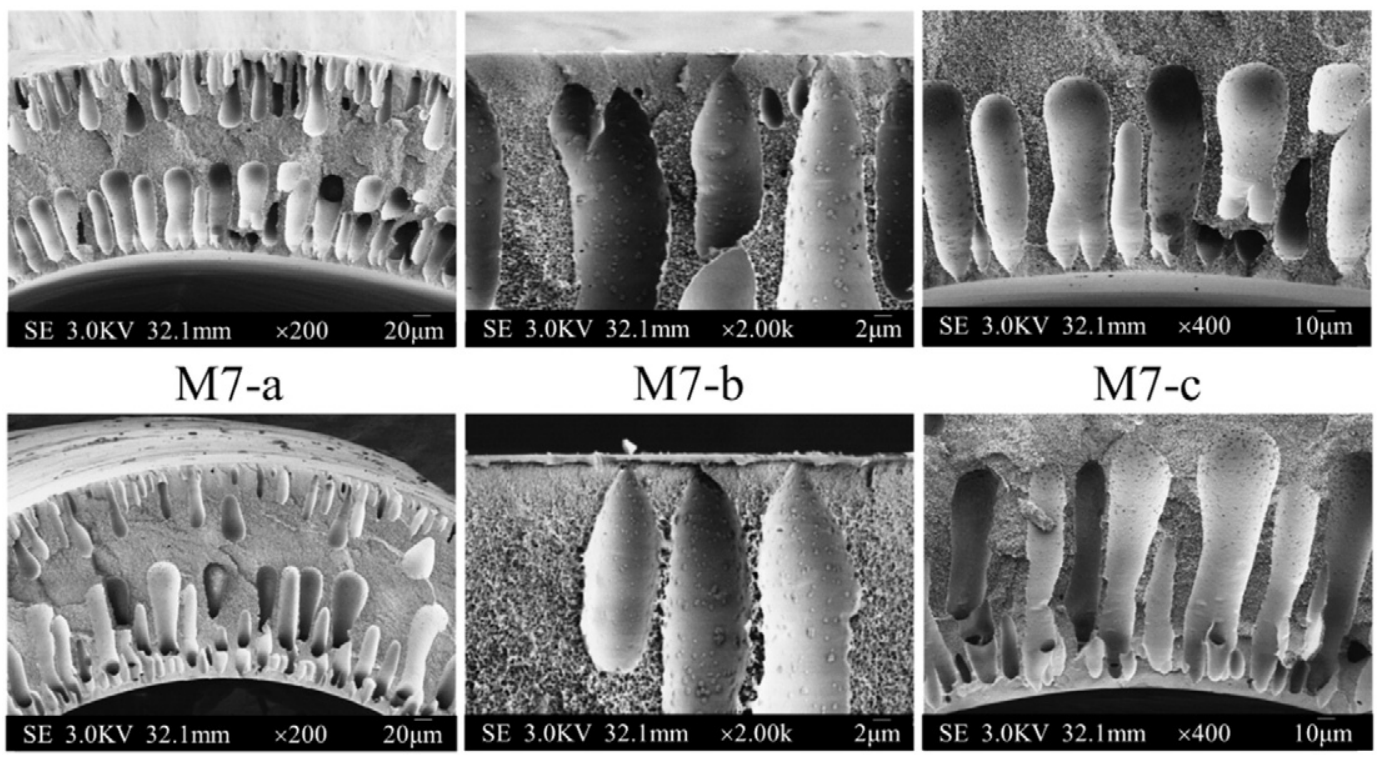

M8-a

M8-b

M8-c
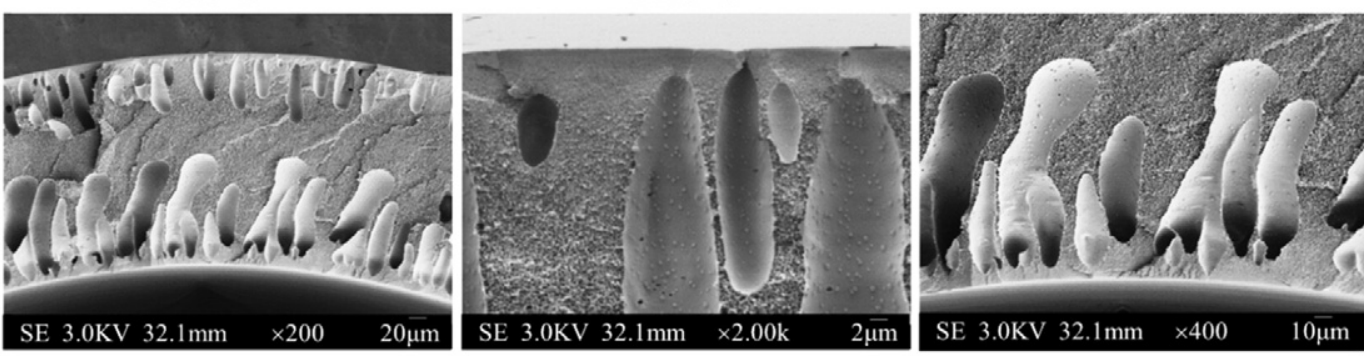

M9-a

M9-b

M9-c

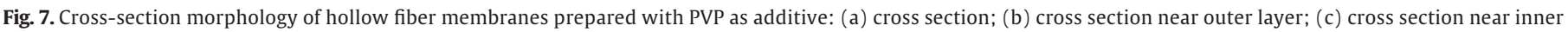
layer.

content of $\mathrm{LiCl}$ increases to $7 \mathrm{wt} . \%$, the macro-voids are eliminated. Clearly, a higher content of $\mathrm{LiCl}$ in the dope retards the formation of macro-voids that is contradict to the commonly observation that the presence of $\mathrm{LiCl}$ in a dope solution enhances solvent (DMAc)-coagulant (water) demixing and conducts to the formation of macrovoids in the membrane $[57,58]$. However, in this study the viscosities of the dope solutions increase drastically by adding more LiCl. The high dope viscosity tends to reduce the solvent/non-solvent exchange speed and delay the growths of the macro-voids. As a result, the macro-voids of the inner layer become longer and narrower and the size and number of finger-like macro-voids close to the outer layer reduce which may lead to the PMIA molecular chain clusters and cross-links. The changes in the casting solutions tended to delay the dope precipitation, and eliminated the formation of finger-like and macro-void structure. As a result, the micro-void structure of the inner layer became longer and narrower and the size and number of finger-like structure across the outer layer reduce.

Fig. 6 shows the cross section morphologies of the membranes prepared using dope containing $5 \mathrm{wt}$.\% $\mathrm{LiCl}$ and different amounts of acetone. When the concentrations of acetone increase, the larger finger-like structure near the outer layer reduces significantly; the

Table 5

PWP and rejection to inorganic salts of PMIA hollow fiber NF membranes spun from different dope solutions.

\begin{tabular}{|c|c|c|c|c|c|}
\hline Membrane code & $\operatorname{PWP}\left(\mathrm{L} \cdot \mathrm{m}^{-2} \cdot \mathrm{bar}^{-1} \cdot \mathrm{h}^{-1}\right)$ & $R\left(\mathrm{Na}_{2} \mathrm{SO}_{4}\right)(\%)$ & $R(\mathrm{NaCl})(\%)$ & $R\left(\mathrm{MgSO}_{4}\right)(\%)$ & $R\left(\mathrm{MgCl}_{2}\right)(\%)$ \\
\hline M1 & $12.29 \pm 0.14$ & $30.91 \pm 0.45$ & $2.23 \pm 0.30$ & $13.11 \pm 0.15$ & $2.07 \pm 0.03$ \\
\hline M2 & $10.88 \pm 0.08$ & $33.89 \pm 1.03$ & $2.99 \pm 0.17$ & $15.59 \pm 0.41$ & $2.13 \pm 0.11$ \\
\hline M3 & $9.59 \pm 0.06$ & $37.05 \pm 0.26$ & $3.19 \pm 0.18$ & $18.55 \pm 0.05$ & $2.69 \pm 0.09$ \\
\hline M4 & $8.63 \pm 0.11$ & $45.69 \pm 0.61$ & $4.73 \pm 0.04$ & $29.09 \pm 1.13$ & $3.52 \pm 0.22$ \\
\hline M5 & $7.82 \pm 0.05$ & $49.68 \pm 1.30$ & $5.23 \pm 0.07$ & $29.18 \pm 0.63$ & $4.12 \pm 0.06$ \\
\hline M6 & $7.57 \pm 0.09$ & $53.94 \pm 0.09$ & $6.20 \pm 0.12$ & $33.44 \pm 0.70$ & $5.11 \pm 0.05$ \\
\hline M7 & $7.12 \pm 0.10$ & $58.26 \pm 0.55$ & $7.38 \pm 1.03$ & $37.16 \pm 0.12$ & $6.29 \pm 0.17$ \\
\hline M8 & $6.82 \pm 0.11$ & $62.98 \pm 0.21$ & $8.21 \pm 0.81$ & $41.63 \pm 1.03$ & $7.06 \pm 0.07$ \\
\hline M9 & $6.56 \pm 0.09$ & $68.54 \pm 1.01$ & $8.80 \pm 0.16$ & $46.57 \pm 0.50$ & $7.45 \pm 0.54$ \\
\hline
\end{tabular}


Table 6

A comparison of performance of our PMIA hollow fiber NF membranes and reported hollow fiber NF membranes.

\begin{tabular}{|c|c|c|c|c|}
\hline Membrane & Fabrication method & Process condition & Membrane performance & Ref. \\
\hline PBI & Phase-inversion technique & $\begin{array}{l}\text { Feed solutions: } 3.4 \mathrm{mmol} / \mathrm{L} \text { of } \mathrm{NaCl}, \mathrm{Na}_{2} \mathrm{SO}_{4}, \mathrm{MgCl}_{2} \\
\text { and } \mathrm{MgSO}_{4} \\
\text { Operation pressure: } 22 \mathrm{bar}\end{array}$ & $\begin{array}{l}\mathrm{PWP}=1.86 \mathrm{~L} \cdot \mathrm{m}^{-2} \cdot \mathrm{h}^{-1} \cdot \mathrm{bar}^{-1} \\
R\left(\mathrm{MgCl}_{2}\right)>R\left(\mathrm{MgSO}_{4}\right)>R\left(\mathrm{Na}_{2} \mathrm{SO}_{4}\right)>R(\mathrm{NaCl})\end{array}$ & {$[35]$} \\
\hline PPESK & Dry/wet phase inversion technique & $\begin{array}{l}\text { Feed solutions: } 100 \text { ppm PEG-600 } \\
\text { Operation pressure: } 3 \text { bar }\end{array}$ & $\begin{array}{l}\mathrm{PWP}=70.33 \mathrm{~L} \cdot \mathrm{m}^{-2} \cdot \mathrm{h}^{-1} \cdot \mathrm{bar}^{-1} \\
\mathrm{MWCO}=600 \mathrm{Da}\end{array}$ & [36] \\
\hline Polypiperazine amide/PPESK & Interfacial polymerization & $\begin{array}{l}\text { Feed solutions: } 1000 \mathrm{ppm} \text { of } \mathrm{Na}_{2} \mathrm{SO}_{4} \\
\text { Operation pressure: } 3.5 \mathrm{bar}\end{array}$ & $\begin{array}{l}\mathrm{PWP}=12.86 \mathrm{~L} \cdot \mathrm{m}^{-2} \cdot \mathrm{h}^{-1} \cdot \mathrm{bar}^{-1} \\
R\left(\mathrm{Na}_{2} \mathrm{SO}_{4}\right)=99 \%\end{array}$ & [37] \\
\hline PES/cSMM & Dry-wet phase inversion method & $\begin{array}{l}\text { Feed solutions: } 0.01 \mathrm{~mol} / \mathrm{L} \text { of } \mathrm{NaCl} \text { and } \mathrm{Na}_{2} \mathrm{SO}_{4} \\
\text { Operation pressure: } 5.51 \mathrm{bar}\end{array}$ & $\begin{array}{l}\mathrm{PWP}=18.15 \mathrm{~L} \cdot \mathrm{m}^{-2} \cdot \mathrm{h}^{-1} \cdot \mathrm{bar}^{-1} \\
R\left(\mathrm{Na}_{2} \mathrm{SO}_{4}\right)>R(\mathrm{NaCl})>49 \%\end{array}$ & [38] \\
\hline $\mathrm{PAI} / \mathrm{CA}$ & Dry-jet wet phase inversion process & $\begin{array}{l}\text { Feed solutions: } 0.01 \mathrm{~mol} / \mathrm{L} \text { of } \mathrm{NaCl}, \mathrm{Na}_{2} \mathrm{SO}_{4}, \mathrm{MgCl}_{2} \\
\text { and } \mathrm{MgSO}_{4} \\
\text { Operation pressure: } 1 \mathrm{bar}\end{array}$ & $\begin{array}{l}\mathrm{PWP}=11.93 \mathrm{~L} \cdot \mathrm{m}^{-2} \cdot \mathrm{h}^{-1} \cdot \mathrm{bar}^{-1} \\
R\left(\mathrm{Na}_{2} \mathrm{SO}_{4}\right)>R\left(\mathrm{MgSO}_{4}\right)>R(\mathrm{NaCl})>R\left(\mathrm{MgCl}_{2}\right)\end{array}$ & [39] \\
\hline $\mathrm{PP} / \mathrm{CMCNa} / \mathrm{FeCl}_{3}$ & Dip-coating method & $\begin{array}{l}\text { Feed solutions: } 500 \mathrm{ppm} \text { of } \mathrm{NaCl} \\
\text { Operation pressure: } 3.0 \mathrm{bar}\end{array}$ & $\begin{array}{l}\mathrm{PWP}=9.9 \mathrm{~L} \cdot \mathrm{m}^{-2} \cdot \mathrm{h}^{-1} \cdot \text { bar }^{-1} \\
\mathrm{MWCO}=700 \mathrm{Da} \\
R(\mathrm{NaCl})=30.4 \%\end{array}$ & {$[40]$} \\
\hline $\mathrm{PP} / \mathrm{CMCNa} / \mathrm{AlCl}_{3}$ & Dip-coating method & $\begin{array}{l}\text { Feed solutions: } 500 \mathrm{ppm} \text { of } \mathrm{NaCl} \text { and } \mathrm{Na}_{2} \mathrm{SO}_{4} \\
\text { Operation pressure: } 3.0 \mathrm{bar}\end{array}$ & $\begin{array}{l}\mathrm{PWP}=9.9 \mathrm{~L} \cdot \mathrm{m}^{-2} \cdot \mathrm{h}^{-1} \cdot \mathrm{bar}^{-1} \\
\mathrm{MWCO}=760 \\
R(\mathrm{NaCl})=28.4 \% \\
R\left(\mathrm{Na}_{2} \mathrm{SO}_{4}\right)=85.3 \%\end{array}$ & [41] \\
\hline PES/SPEEK & Dip-coating method & $\begin{array}{l}\text { Feed solutions: } 500 \mathrm{ppm} \text { of } \mathrm{NaCl}, \mathrm{Na}_{2} \mathrm{SO}_{4} \text {, } \\
\text { and } \mathrm{MgCl}_{2} \\
\text { Operation pressure: } 2.0 \mathrm{bar}\end{array}$ & $R\left(\mathrm{Na}_{2} \mathrm{SO}_{4}\right)>R(\mathrm{NaCl})>R\left(\mathrm{MgCl}_{2}\right)$ & [42] \\
\hline PMIA & Dry-jet wet spinning technique & $\begin{array}{l}\text { Feed solutions: } 3.4 \mathrm{mM} \text { of } \mathrm{NaCl}, \mathrm{Na}_{2} \mathrm{SO}_{4}, \mathrm{MgCl}_{2} \\
\text { and } \mathrm{MgSO}_{4} \\
\text { Operation pressure: } 7.0 \mathrm{bar}\end{array}$ & $\begin{array}{l}\mathrm{PWP}=6.56-12.29 \mathrm{~L} \cdot \mathrm{m}^{-2} \cdot \mathrm{h}^{-1} \cdot \mathrm{bar}^{-1} \\
R\left(\mathrm{Na}_{2} \mathrm{SO}_{4}\right)>R\left(\mathrm{MgSO}_{4}\right)>R(\mathrm{NaCl})>R\left(\mathrm{MgCl}_{2}\right) \\
\text { MWCO }=911-3804 \mathrm{Da}\end{array}$ & Current work \\
\hline
\end{tabular}

more sponge-like structure occupies the membrane middle section (Fig. 6 M4-a, M5-a, M6-a); the macro-voids near the inner layer become narrower (Fig. 6 M4-c, M5-c, M6-c); and the thicknesses of the outer skin dense layer (Fig. 6 M4-b, M5-b, M6-b) increase. According to Fig. 4, the viscosities of the dope solutions slightly increase as the concentrations of acetone increase from 4 to 8 wt.\%. Since dope viscosity plays an important role in the formation of macro-voids [59], the slightly increased viscosities of the three dope solutions (M4 to M6) result in a slightly reduced macro-void near the inner surface. However, acetone has a low boiling point. The evaporation of acetone in the gas-dope contact interface increases the polymer concentration in the outer surface of the nascent hollow fiber. Hence, as the acetone concentration increases, more acetone vaporizes from the membrane outer surface and polymer concentration near the outer surface is further increased. It leads to a higher dope viscosity and the formation of a denser skin layer with more significantly reduced macro-voids in the outer layer than in the inner layer of the membrane.

The cross-section structures of membranes fabricated from dope solutions with 5 wt.\% LiCl, 6 wt.\% acetone and different amounts of PVP as additives are shown in Fig. 7. By adding a low concentration of PVP (0.5 wt.\%), the SEM images of the membrane cross-section, outer layer and inner layer (M7-a, b, c) show relatively larger macro-voids and finger-like structures as well as thinner outer and inner skin layers than those of the membranes spun from a dope solution containing the same amount of $\mathrm{LiCl}$, acetone without PVP (M5-a, b, c). Since PVP is a hydrophilic material and is typically used as the pore forming agent, the addition of PVP may facilitate the diffusion of water and the formation of larger macro-voids. Furthermore, PVP is a non-solvent, adding it into the dope solution will push the dope composition closer to the binodal curve. At this situation, the polymer precipitation is fast and the thicknesses of the outer and inner skin layers are reduced. Interestingly, as the PVP concentrations increase to $1.5 \mathrm{wt} . \%$ and $3.0 \mathrm{wt} . \%$, a relatively suppressed macro-void and thicker skin layers are observed (Fig. 7 M8 and M9). Many membrane scientists claim that the factors potentially assisting macro-void formation are non-solvent moving front, precipitation front, surface weakness, flow instability, capillary flow, moisture sorption, low viscosity, etc. [60,61]. Generally, a high dope viscosity may hinder the growths of macro-voids and finger-like structures. The observations of smaller macro-voids at higher PVP concentrations may stem from the fact that the dope viscosities are significantly increased when adding more PVP.

\subsection{Effect of the additives on the membrane separation performance and charge characteristics}

Table 5 lists the PWP and salt rejections of all 9 membranes. The PWP values gradually decrease with the increase in the $\mathrm{LiCl}$, acetone, and PVP contents in the dopes. In this study, all membranes contain asymmetric structures and the PWP is affected by factors including skin layer thickness, pore size, pore size distribution, tortuosity, and sub-layer structures. Recall that the thickness of the skin layer slightly increases by increasing the concentrations of LiCl, acetone, and PVP. Moreover, the macro-void and fingerlike structures provide an open membrane structure with lower degree of tortuosity where water can easily pass through. By increasing the $\mathrm{LiCl}$, acetone, and PVP concentrations in the dopes, the morphologies of the membrane change from large macro-void and finger-like structure to small sponge-like structures. Thus, the thicker skin layer and more sponger-like macro-voids lead to the decrease in PWP.

The charge characteristics of PMIA hollow fiber NF membranes are studied in terms of the rejections to four different inorganic salts, i.e., $\mathrm{Na}_{2} \mathrm{SO}_{4}, \mathrm{MgSO}_{4}, \mathrm{NaCl}$ and $\mathrm{MgCl}_{2}$. As listed in Table 5, the salt rejections of all membranes decrease in the same order of $R\left(\mathrm{Na}_{2} \mathrm{SO}_{4}\right)>R\left(\mathrm{MgSO}_{4}\right)>R(\mathrm{NaCl})>R\left(\mathrm{MgCl}_{2}\right)$. For salts with the same cation $\left(\mathrm{Na}^{+}\right.$or $\left.\mathrm{Mg}^{2+}\right)$, the PMIA NF membranes exhibit a higher rejection to high-valence anions than to low-valence anions $\left(R\left(\mathrm{Na}_{2} \mathrm{SO}_{4}\right)>R(\mathrm{NaCl}), R\left(\mathrm{MgSO}_{4}\right)>R\left(\mathrm{MgCl}_{2}\right)\right)$. This is because the hydration ion radius of $\mathrm{SO}_{4}^{2-}(0.38 \mathrm{~nm})$ is larger than that of $\mathrm{Cl}^{-}$ $(0.33 \mathrm{~nm})$ [62]. For salts with the same anion $\left(\mathrm{SO}_{4}^{2-}\right.$ and $\left.\mathrm{Cl}^{-}\right)$, the PMIA NF membranes show a higher rejection to low-valence cation $\left(\mathrm{Na}^{+}\right)$than to high-valence cation $\left(\mathrm{Mg}^{2+}\right)$, which contributed 
to the higher electrical compulsion of the high-valence cation for its higher positive valence [63]. Thus, the salt rejections follow the order of $R\left(\mathrm{Na}_{2} \mathrm{SO}_{4}\right)>R\left(\mathrm{MgSO}_{4}\right), R(\mathrm{NaCl})>R\left(\mathrm{MgCl}_{2}\right)$. Taken together, the rejections to four electrolytes are in the order of $R\left(\mathrm{Na}_{2} \mathrm{SO}_{4}\right)>R\left(\mathrm{MgSO}_{4}\right)>R(\mathrm{NaCl})>R\left(\mathrm{MgCl}_{2}\right)$ at the same molar concentration.

It can also be observed from Table 5 that the salt rejections increase with the increase in the contents of $\mathrm{LiCl}$, acetone,
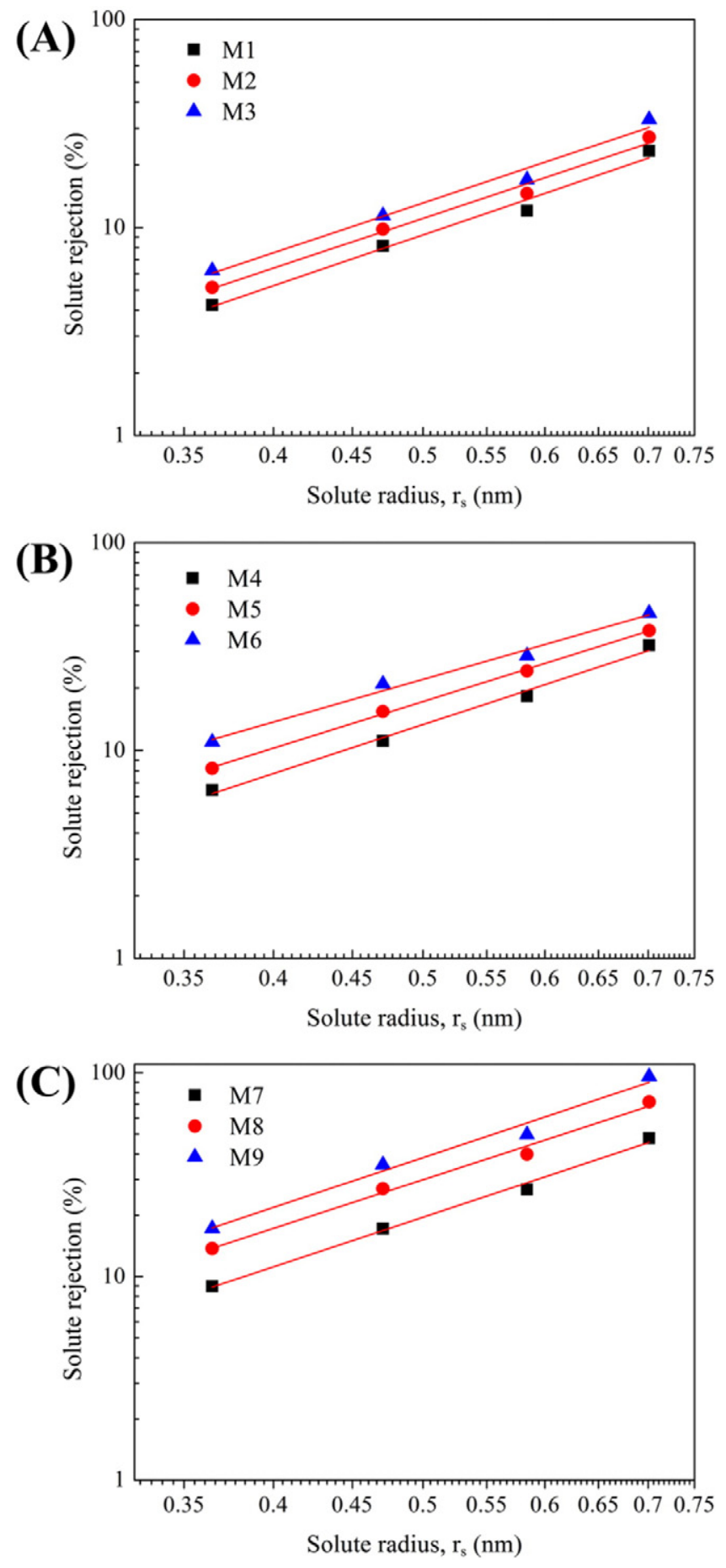

Fig. 8. Solute rejection curves plotted on a log-normal probability coordinate system of PMIA hollow fiber NF membranes spun from different dope solutions.
Table 7

Mean effective pore size $\left(\mu_{p}\right)$, geometric standard deviation $\left(\sigma_{p}\right)$ and MWCO of PMIA hollow fiber NF membranes spun from different dope solutions.

\begin{tabular}{llll}
\hline Membrane code & $\mu_{p}(\mathrm{~nm})$ & $\sigma_{p}$ & MWCO (Da) \\
\hline M1 & 0.978 & 1.229 & 3804 \\
M2 & 0.921 & 1.234 & 3317 \\
M3 & 0.859 & 1.234 & 2771 \\
M4 & 0.862 & 1.239 & 2826 \\
M5 & 0.793 & 1.252 & 2357 \\
M6 & 0.737 & 1.278 & 2080 \\
M7 & 0.727 & 1.231 & 1807 \\
M8 & 0.617 & 1.236 & 1203 \\
M9 & 0.556 & 1.229 & 911 \\
\hline
\end{tabular}

and PVP in the dopes. As well known, the rejection to salts for NF membranes not only depends on the electrostatic action between the membrane and the ions, but also the size exclusion effect [62]. Table 7 indicates that the mean pore sizes of all membranes decrease as the concentrations of $\mathrm{LiCl}$, acetone, and PVP increase. These results can explain the improvements of the salt rejections. Meanwhile, the performance of our PMIA hollow fiber NF membranes and other reported hollow fiber NF membranes is given in Table 6 . The performance of the home-made PMIA hollow fiber NF membranes is comparable to other NF membranes.

3.4. Effect of the additives on the membrane pore size and pore size distribution

The curves of solute rejection vs. solute Stokes radius are plotted on the log-normal probability graphs in Fig. 8. Linear fitting curves to the date with high correlation coefficients $\left(r^{2}>95 \%\right)$ are obtained. Table 7 lists the mean effective pore radius $\mu_{p}$ at $R_{T}=50 \%$, the geometric standard deviation $\sigma_{p}$, and MWCO. Fig. 9 shows the curves of the cumulative pore size distributions and probability density functions of the PMIA hollow fiber membranes against the pore sizes calculated from Eqs. (3), (4) and (6). According to Fig. 9, the mean pore size becomes smaller by increasing the $\mathrm{LiCl}$ content. Note that $\mathrm{LiCl}$ is a water-soluble inorganic salt. At a low concentration (3 wt.\%) of $\mathrm{LiCl}$ in the dope (M1), it facilitates water diffusing into the dope solution. Hence it results in a rapid phase separation and leads to the formation of bigger pores on the membrane surface. However, when the concentration of $\mathrm{LiCl}$ increases to $5 \mathrm{wt} . \%$ and $7 \mathrm{wt} . \%$ in the dope (M2 and M3), the viscosities of the dope solutions increase significantly. The strong interactions among the components of the dope tend to delay the polymer precipitation and it results in the formation of smaller pores on the membrane surface. It can also be observed that the mean pore size is reduced by increasing acetone concentration in the dope (M4, M5 and M6 in Table 7), which may be due to acetone that rapidly vaporizes to air before the nascent membrane entering the coagulant bath. It results in a more concentrated polymer solution near the outer surface, and therefore a denser top skin layer with a smaller mean pore size and a narrower pore size distribution is formed. Additionally, the mean pore size and pore size distribution become smaller and narrower with the increases in the PVP concentration (M7, M8 and M9 in Table 7). The presence of PVP in the dope solution not only promotes the formation of sponge-like structure but also influences the formation of pores on the surface [64]. During phase inversion process, PVP, as a water soluble polymer, is preferentially located in the pore surface, which contributed its high affinity to water. Note that PVP is difficult to be removed thoroughly. The residual PVP in the hollow fiber membranes will lead to the reduction of pore size or even blocking the pores. 
(A)

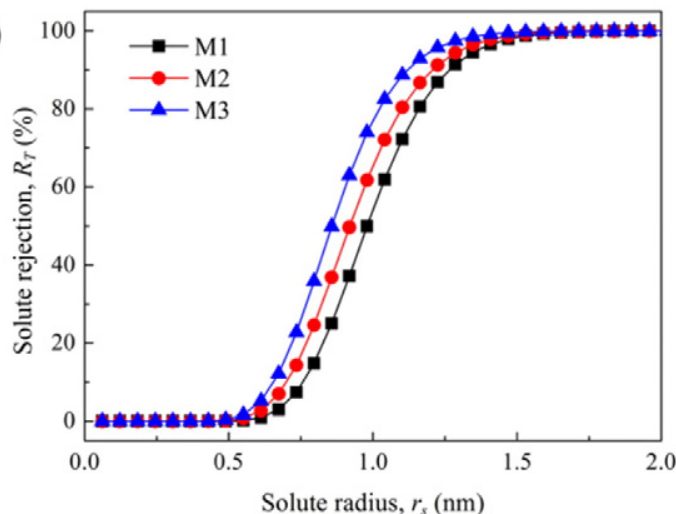

(B)

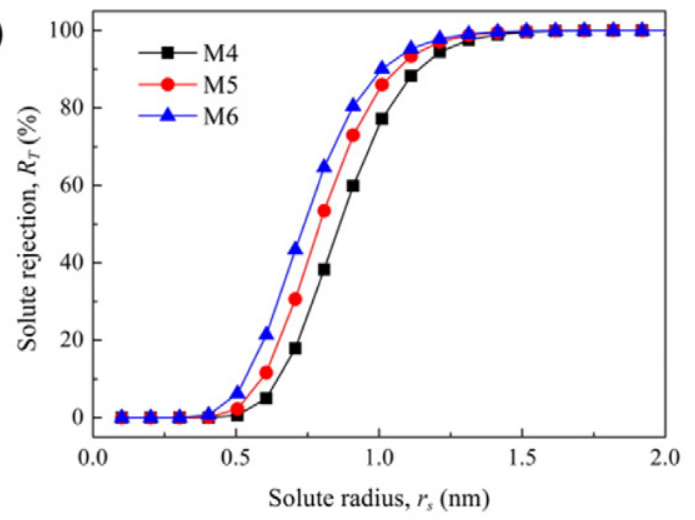

(C)

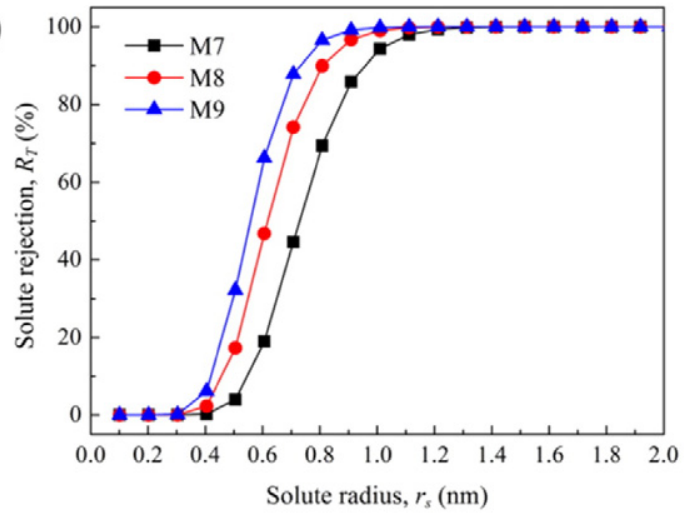

(D)

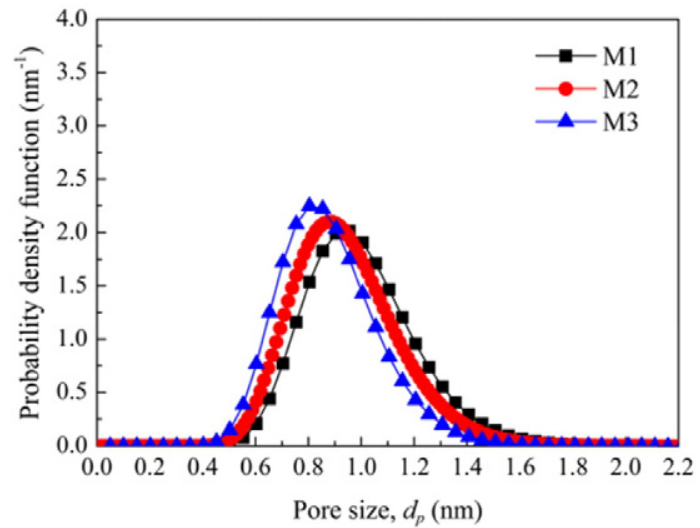

(E)

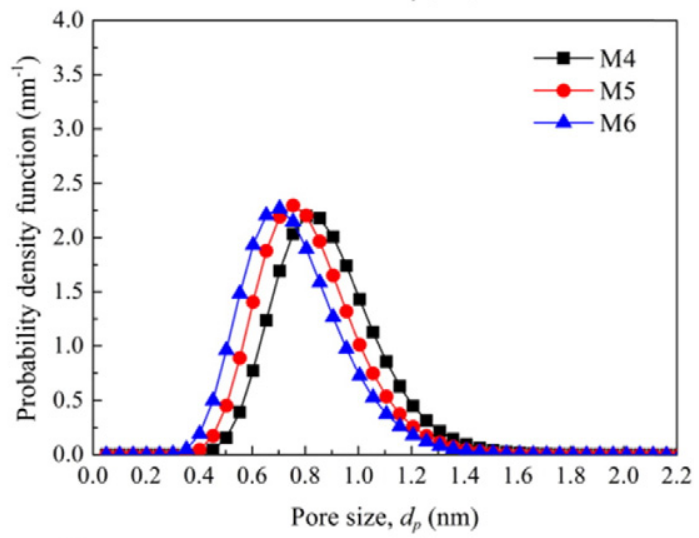

(F)

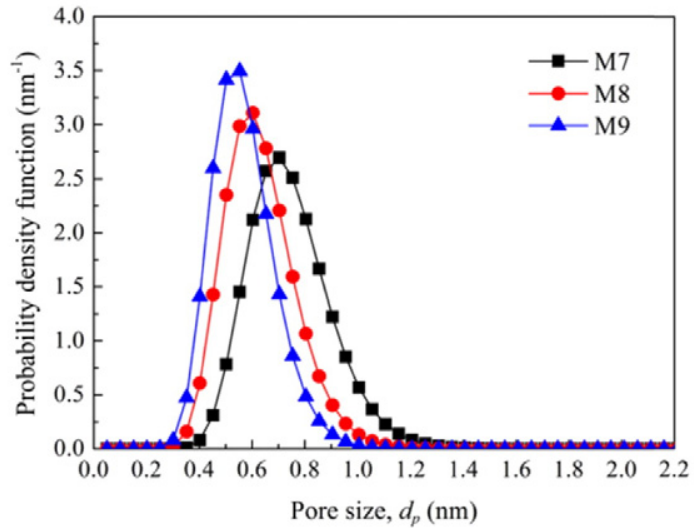

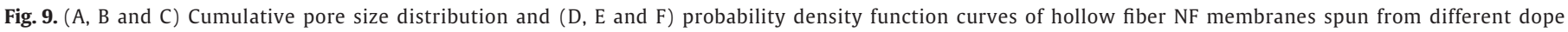
solutions.

\subsection{Effect of the additives on the membrane surface properties}

The AFM images of the outer surfaces of all PMIA NF membranes are illustrated in Fig. 10, which shows the 2D and 3D images at a scanning area of $5 \mu \mathrm{m} \times 5 \mu \mathrm{m}$. The bright yellowish and dark spots in the images represent the nodule aggregates formed on the membrane surfaces. It can be observed that the size of the nodule aggregates gradually decreases and the distance among the nodule aggregates increases with the increase in the $\mathrm{LiCl}$ concentration in the dopes (from M1 to M3). Table 8 lists the roughness parameters of the membrane surfaces including the average roughness $\left(R_{a},\right)$, the root mean square roughness $\left(R_{q}\right)$ and the maximum roughness $\left(R_{\max }\right)$, respectively. The roughness of the membrane surfaces decreases as the $\mathrm{LiCl}$ content increases. These results are probably due to the increases in viscosity of the dope solutions caused by adding $\mathrm{LiCl}$, since a high viscosity of the dope solution delays the phase inversion process and leads to the formation of a relatively smooth membrane surface.

According to Fig. 10 (Continued-1) and Table 8, the surfaces of membranes (M4 to M6) become smoother when more acetone is added into the dope solutions. Two reasons may be accounted for these results: first, the addition of acetone increases the dope viscosity; and second, the fast evaporation of acetone results in the formation of a denser outer surface.

Fig. 10 (Continued-2) shows that the introduction of PVP in the dopes reduces the size of the nodule aggregates and leads to the formations of smoother membrane surfaces (M7 to M9). As discussed earlier, when using PVP as an additive, it increases the dope viscosity which delays the mutual diffusion between solvent 
and non-solvent and suppresses the macro-pore formation. It is well accepted that the decrease in pore size and nodule size normally reduces the values of membrane surface roughness parameters [65]. Note that the estimated mean pore sizes of the membranes decrease as the concentrations of PVP increase. Therefore, a smaller mean pore size is in accordance with the smoother membrane surface shown in Fig. 10 (Continued-2) and smaller roughness parameters given in Table 8.

\subsection{Effect of the additives on the membrane mechanical properties}

Table 9 lists the mechanical properties of all PMIA hollow fiber membranes. The stress values at break increase from $13.57 \pm$ $0.13 \mathrm{MPa}$ for M1 to $16.73 \pm 0.15 \mathrm{MPa}$ for M3 by increasing $\mathrm{LiCl}$ concentration in the dopes. Similar tendencies are observed for membranes from M4 to M6 (with different amounts of acetone) and M7 to M9 (with different amounts of PVP). The elongation at break and the elastic modulus follow the similar trends that when compositions of other materials in the dopes are fixed the elongation at break and elastic modulus monotonously increase with the increase in the concentration of acetone or PVP. These results can be attributed to the changes in the membrane structures. Finger-like voids are commonly related to the weak mechanical strength which is not usually desired for polymer and ceramic hollow fiber membranes [66]. As discussed in Section 3.2, the proportion of the finger-like structure decreases and the sponge-like structure increases with the increases in the $\mathrm{LiCl}$, acetone, and PVP contents of the dope solutions. It shall be the reason for the improvements of the membrane mechanical strengths.

\section{Conclusion}

The PMIA hollow fiber NF membranes were fabricated with various concentrations of $\mathrm{LiCl}$, acetone and PVP used as nonsolvent additives in the dope solutions via the dry-jet wet spinning technology. As the concentrations of $\mathrm{LiCl}$, acetone and PVP increased the following observations were obtained including: (1) the dope viscosities increased; (2) the membrane morphologies changed from finger-like to sponge-like, and the skin-layer thickness slightly increased; (3) PWP decreased; (4) the salt rejections increased and the salt rejections decreased in the order of $R\left(\mathrm{Na}_{2} \mathrm{SO}_{4}\right)>R\left(\mathrm{MgSO}_{4}\right)>R(\mathrm{NaCl})>R\left(\mathrm{MgCl}_{2}\right)$; (5) the membrane

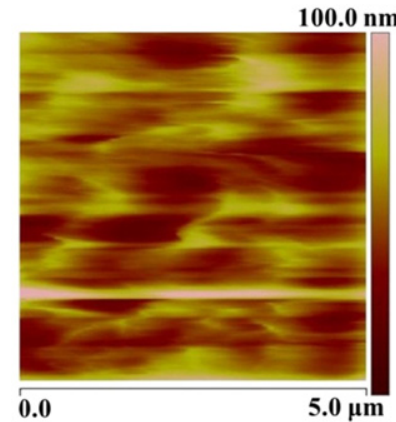

M1-a

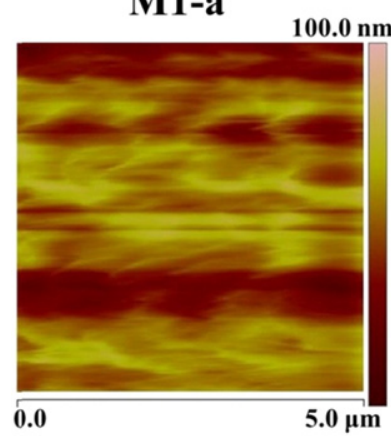

M2-a

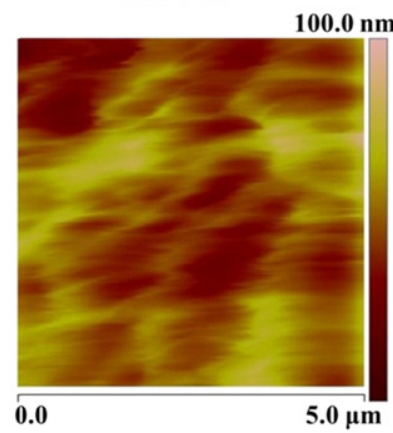

M3-a

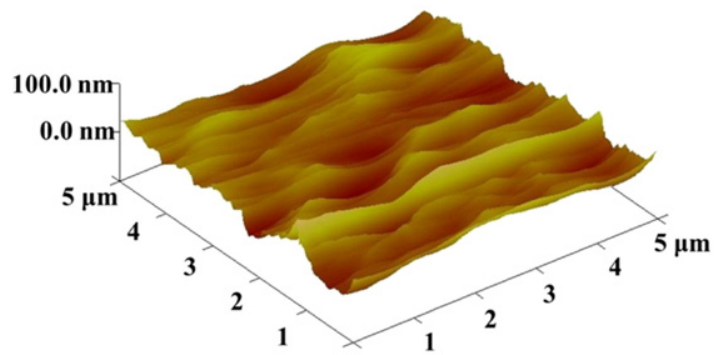

M1-b

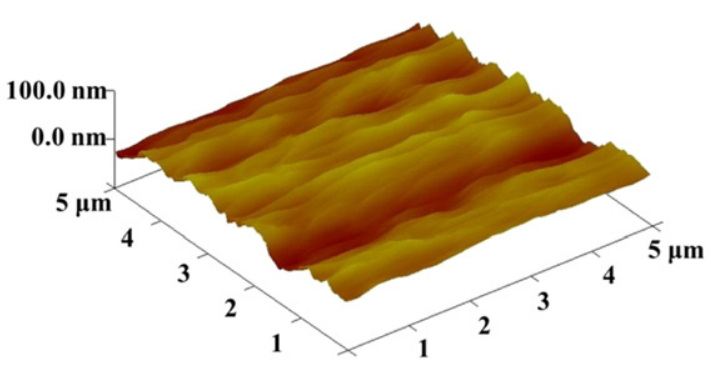

M2-b

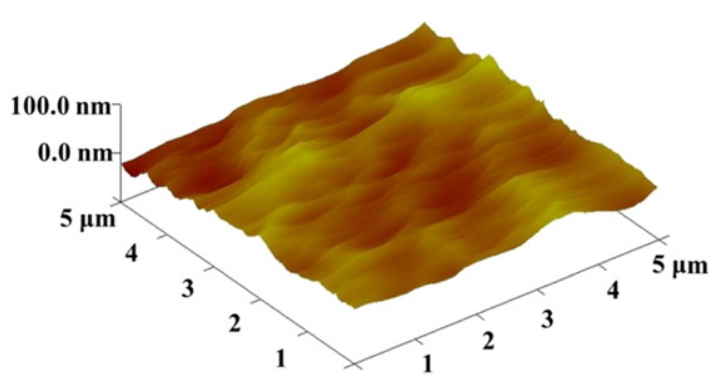

M3-b 


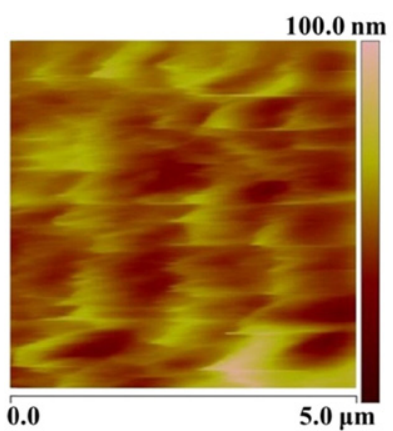

M4-a

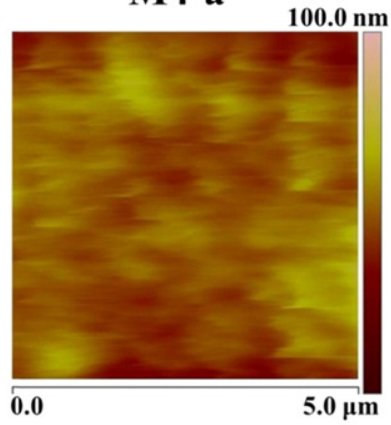

M5-a

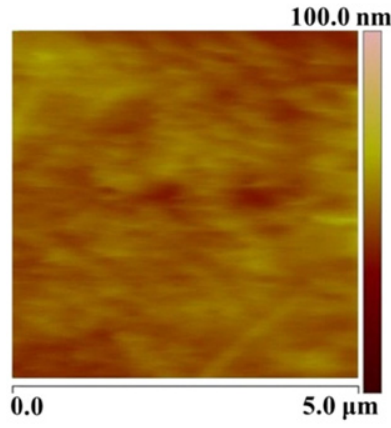

M6-a

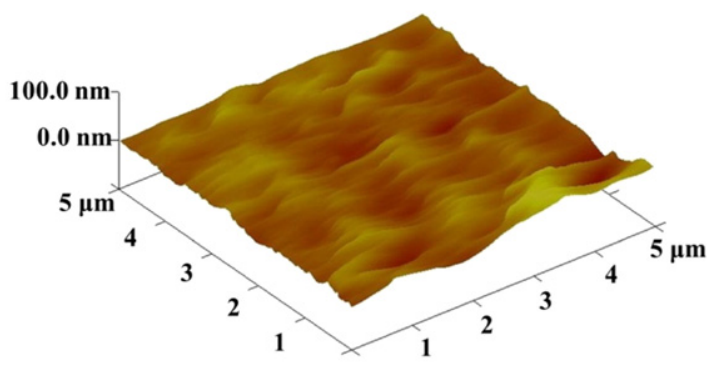

M4-b

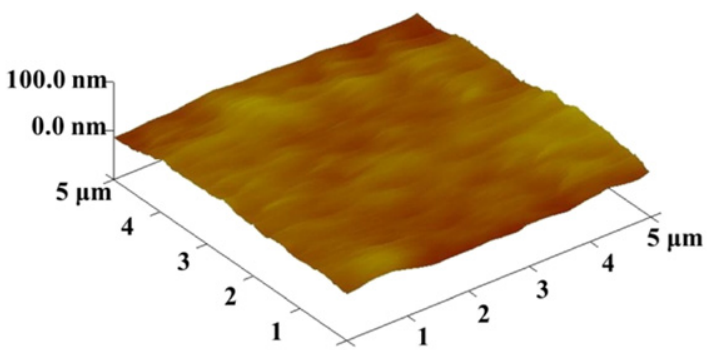

M5-b

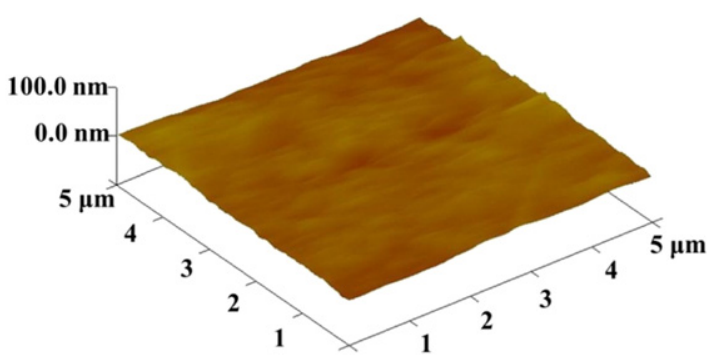

M6-b

Fig. 10 (continued).

mean pore sizes and the MWCO decreased; (6) the membrane surface roughness decreased and became smoother; and (7) the mechanical strength of the membranes increased.

Summarizing the above results we may conclude that with proper concentrations of $\mathrm{LiCl}$, acetone and PVP in the dope it is possible to fabricate PMIA hollow fiber NF membranes with desired structures and separation performances. The PMIA hollow fiber NF membranes may be of potential to be utilized in the drinking water and wastewater treatment.

\section{Nomenclature}

PMIA poly( $m$-phenylene isophthalamide)

MWCO molecular weight cut-off (Da)

$\mathrm{NF} \quad$ nanofiltration

UF ultrafiltration

RO reverse osmosis

TFC thin-film composite

IP interfacial polymerization

PBI polybenzimidazole

PPESK poly(phthalazinone ether sulfone ketone)

PES polyethersulfone

PIP piperazine
TMC trimesoyl chloride

CMCNa carboxymethyl cellulose

PP polypropylene

SPEEK sulfonated poly (ether ether ketone)

CA cellulose acetate

PES polyether sulfone

$\mathrm{LiCl}$ lithium chloride

$\mathrm{NaCl}$ sodium chloride

$\mathrm{Na}_{2} \mathrm{SO}_{4}$ sodium sulfate

$\mathrm{MgCl}_{2}$ magnesium chloride

$\mathrm{MgSO}_{4}$ magnesium sulfate

DMAc N,N-dimethylacetamide

PVP K15 poly vinylpyrrolidone K15

PWP pure water permeation $\left(\mathrm{L} \cdot \mathrm{m}^{-2} \cdot \mathrm{bar}^{-1} \cdot \mathrm{h}^{-1}\right)$.

Q Water permeation volumetric flow rate $\left(\mathrm{L} \cdot \mathrm{h}^{-1}\right)$

A membrane effective filtration area $\left(\mathrm{m}^{2}\right)$

$\Delta P \quad$ transmembrane pressure drop (bar)

$R \quad$ rejection (\%)

$C_{p} \quad$ permeate concentrations $(\mathrm{g} / \mathrm{L})$

$\mathrm{C}_{\mathrm{f}} \quad$ feed concentrations $(\mathrm{g} / \mathrm{L})$

Re Reynolds number

$R_{T} \quad$ solute rejection (\%) 


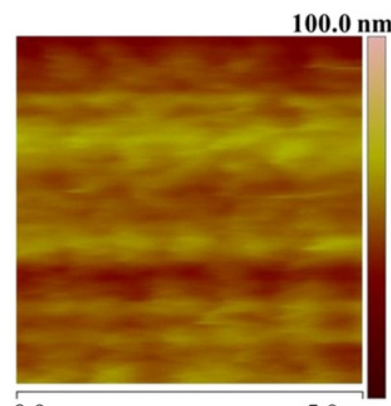

0.0

$5.0 \mu \mathrm{m}$

M7-a

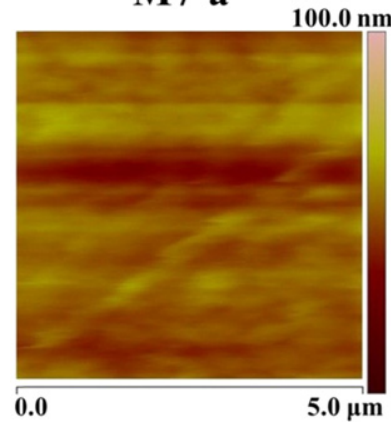

M8-a

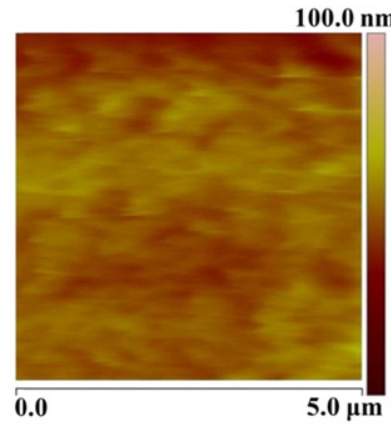

M9-a

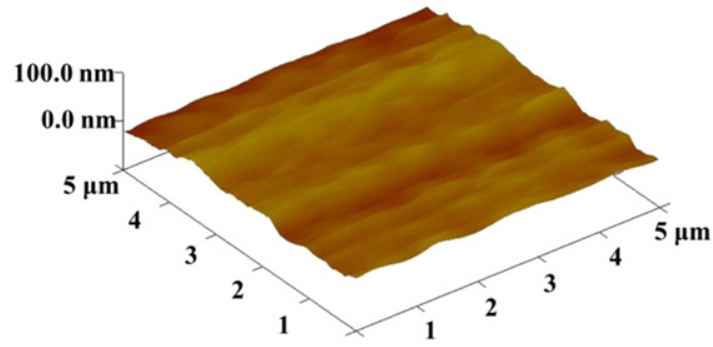

M7-b

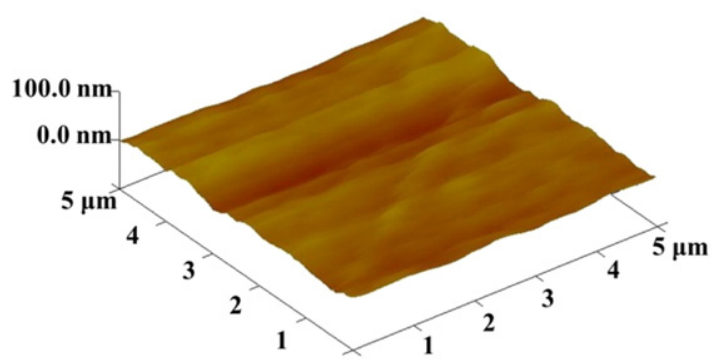

M8-b

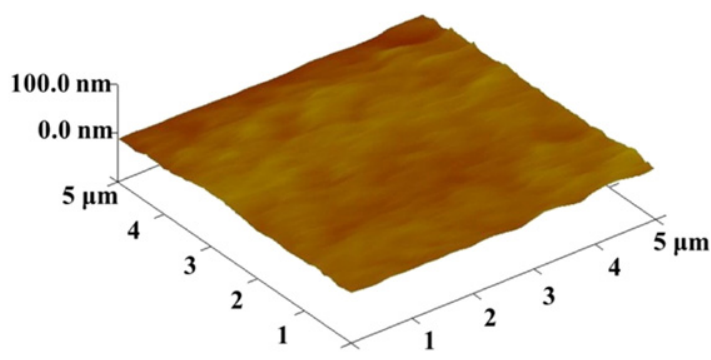

M9-b

Fig. 10 (continued)

Table 8

Roughness parameters of the PMIA hollow fiber NF membranes spun from different dope solutions.

\begin{tabular}{lccc}
\hline Membrane code & $R_{a}(\mathrm{~nm})$ & $R_{q}(\mathrm{~nm})$ & $R_{\max }(\mathrm{nm})$ \\
\hline M1 & 13.9 & 10.7 & 103 \\
M2 & 12.4 & 9.99 & 70.8 \\
M3 & 11.1 & 8.97 & 70.3 \\
M4 & 9.81 & 7.47 & 73.7 \\
M5 & 6.68 & 5.24 & 46.0 \\
M6 & 4.02 & 3.15 & 30.9 \\
M7 & 6.67 & 5.15 & 37.5 \\
M8 & 5.97 & 4.54 & 37.9 \\
M9 & 4.82 & 3.88 & 32.8 \\
\hline
\end{tabular}

$r_{s} \quad$ solute radius $(\mathrm{nm})$

$\mu_{\mathrm{s}} \quad$ geometric mean radius (nm)

$\sigma_{g} \quad$ geometric standard deviation

$\mu_{p} \quad$ mean effective pore radius (nm)

$\sigma_{p} \quad$ geometric standard deviation

$d_{p} \quad$ effective pore radius (nm)

$M_{W} \quad$ molecular weight $(\mathrm{g} / \mathrm{mol})$

PSF polyethersulfone

$\mathrm{Ra}$ solubility parameter distance

$\delta_{d}, \delta_{p}, \delta_{h}$ solubility parameter

SEM scanning electron microscopy

AFM atomic force microscope

Table 9

Mechanical properties of the PMIA hollow fiber NF membranes spun from different dope solutions.

\begin{tabular}{|c|c|c|c|c|c|c|c|c|c|}
\hline Membrane code & M1 & M2 & M3 & M4 & M5 & M6 & M7 & M8 & M9 \\
\hline Elongation at break (\%) & $49.25 \pm 0.57$ & $49.75 \pm 1.65$ & $53.75 \pm 0.74$ & $49.50 \pm 1.37$ & $52.25 \pm 0.09$ & $53.0 \pm 0.68$ & $43.5 \pm 0.77$ & $44.1 \pm 0.48$ & $49.0 \pm 0.58$ \\
\hline Stress at break (MPa) & $13.57 \pm 0.13$ & $15.11 \pm 0.14$ & $16.73 \pm 0.15$ & $15.02 \pm 0.08$ & $16.46 \pm 0.06$ & $18.15 \pm 0.19$ & $16.49 \pm 0.04$ & $20.19 \pm 0.01$ & $21.13 \pm 0.96$ \\
\hline Elastic modulus (MPa) & $13.23 \pm 0.04$ & $14.19 \pm 0.20$ & $19.23 \pm 0.07$ & $15.20 \pm 0.29$ & $15.93 \pm 0.07$ & $19.22 \pm 0.11$ & $17.38 \pm 0.21$ & $23.56 \pm 0.17$ & $24.29 \pm 0.17$ \\
\hline
\end{tabular}




\section{Acknowledgments}

This work was financially supported by the National Natural Science Foundation of China (Nos. 21176245 and 50978245), the National Science and Technology Support Program of China (Nos. 2012BAJ25B02 and 2012BAJ25B06) and the special fund of State Key Joint Laboratory of Environment Simulation and Pollution Control (No. 12L02ESPC).

\section{References}

[1] A.I. Schäfer, A.G. Fane, T.D. Waite, Nanofiltration: Principles and Applications, Elsevier Advanced Technology, 2005.

[2] X. Lu, X. Bian, L. Shi, Preparation and characterization of NF composite membrane, J. Membr. Sci. 210 (2002) 3-11.

[3] W.R. Bowen, J.S. Welfoot, Modelling the performance of membrane nanofiltration-critical assessment and model development, Chem. Eng. Sci. 57 (2002) 1121-1137.

[4] M. Mulder, Basic Principles of Membrane Technology, Second Edition Kluwer Academic Pub, 1996.

[5] L.P. Raman, M. Cheryna, N. Rajagopalan, Consider nanofiltration for membrane separations, Chem. Eng. Prog. 90 (3) (1994) 68-74 (United States Medium: X; Size:).

[6] P. Eriksson, Nanofiltration extends the range of membrane filtration, Environ. Prog. 7 (1988) 58-62

[7] W. Richard Bowen, A. Wahab Mohammad, A theoretical basis for specifying nanofiltration membranes - dye/salt/water streams, Desalination 117 (1998) 257-264.

[8] C. Visvanathan, B.D. Marsono, B. Basu, Removal of THMP by nanofiltration: effects of interference parameters, Water Res. 32 (1998) 3527-3538.

[9] G.I.M. Worm, M.M. Nederlof, J.C. van Dijk, Liquid velocity-permeate quality relationship for capillary nanofiltration, Desalination 139 (2001) 255-262.

[10] W.R. Bowen, T.A. Doneva, H.-B. Yin, Separation of humic acid from a model surface water with PSU/SPEEK blend UF/NF membranes, J. Membr. Sci. 206 (2002) 417-429.

[11] B. Cyna, G. Chagneau, G. Bablon, N. Tanghe, Two years of nanofiltration at the Mérysur-Oise plant, France, Desalination 147 (2002) 69-75.

[12] M. Thanuttamavong, K. Yamamoto, J. Ik Oh, K. Ho Choo, S. June Choi, Rejection characteristics of organic and inorganic pollutants by ultra low-pressure nanofiltration of surface water for drinking water treatment, Desalination 145 (2002) 257-264.

[13] A. Gorenflo, D. Velázquez-Padrón, F.H. Frimmel, Nanofiltration of a German groundwater of high hardness and NOM content: performance and costs, Desalination 151 (2003) 253-265.

[14] A. Akbari, S. Desclaux, J.C. Rouch, J.C. Remigy, Application of nanofiltration hollow fibre membranes, developed by photografting, to treatment of anionic dye solutions, J. Membr. Sci. 297 (2007) 243-252.

[15] I.-C. Kim, K.-H. Lee, Dyeing process wastewater treatment using fouling resistant nanofiltration and reverse osmosis membranes, Desalination 192 (2006) 246-251.

[16] I. Koyuncu, Reactive dye removal in dye/salt mixtures by nanofiltration membranes containing vinylsulphone dyes: effects of feed concentration and cross flow velocity, Desalination 143 (2002) 243-253.

[17] W.-J. Lau, A.F. Ismail, Polymeric nanofiltration membranes for textile dye wastewater treatment: Preparation, performance evaluation, transport modelling, and fouling control - a review, Desalination 245 (2009) 321-348.

[18] J.-J. Qin, M.H. Oo, K.A. Kekre, Nanofiltration for recovering wastewater from a specific dyeing facility, Sep. Purif. Technol. 56 (2007) 199-203.

[19] P.S. Zhong, N. Widjojo, T.-S. Chung, M. Weber, C. Maletzko, Positively charged nanofiltration (NF) membranes via UV grafting on sulfonated polyphenylenesulfone (sPPSU) for effective removal of textile dyes from wastewater, J. Membr. Sci. 417-418 (2012) 52-60.

[20] H. Chmiel, M. Kaschek, C. Blöcher, M. Noronha, V. Mavrov, Concepts for the treatment of spent process water in the food and beverage industries, Desalination 152 (2003) 307-314.

[21] A. Hafez, M. Khedr, H. Gadallah, Wastewater treatment and water reuse of food processing industries. Part II: techno-economic study of a membrane separation technique, Desalination 214 (2007) 261-272.

[22] S. Darvishmanesh, F. Tasselli, J.C. Jansen, E. Tocci, F. Bazzarelli, P. Bernardo, P. Luis, J Degrève, E. Drioli, B. Van der Bruggen, Preparation of solvent stable polyphenylsulfone hollow fiber nanofiltration membranes, J. Membr. Sci. 384 (2011) 89-96.

[23] N.F. Ghazali, F.C. Ferreira, A.J.P. White, A.G. Livingston, Chiral separation by enantioselective inclusion complexation-organic solvent nanofiltration, Desalination 199 (2006) 398-400

[24] R. Molinari, M.G. Buonomenna, A. Cassano, E. Drioli, Recovery and recycle of tannins in the leather industry by nanofiltration membranes, J. Chem. Technol. Biotechnol. 79 (2004) 361-368.

[25] R. Othman, A.W. Mohammad, M. Ismail, J. Salimon, Application of polymeric solvent resistant nanofiltration membranes for biodiesel production, J. Membr. Sci. 348 (2010) 287-297.

[26] I. Sereewatthanawut, A.T. Boam, A.G. Livingston, Polymeric membrane nanofiltration and its application to separations in the chemical industries, Macromol. Symp. 264 (2008) 184-188.

[27] K.Y. Wang, T.-S. Chung, The characterization of flat composite nanofiltration membranes and their applications in the separation of cephalexin, J. Membr. Sci. 247 (2005) 37-50.
[28] K.Y. Wang, T.-S. Chung, Polybenzimidazole nanofiltration hollow fiber for cephalexin separation, AICHE J. 52 (2006) 1363-1377.

[29] K.Y. Wang, T.-S. Chung, J.-J. Qin, Polybenzimidazole (PBI) nanofiltration hollow fiber membranes applied in forward osmosis process, J. Membr. Sci. 300 (2007) 6-12.

[30] R.J. Petersen, Composite reverse osmosis and nanofiltration membranes, J. Membr. Sci. 83 (1993) 81-150.

[31] R.W. Baker, Overview of membrane science and technology, Membrane Technology and Applications, John Wiley \& Sons, Ltd., 2004, pp. 1-14.

[32] J. Ji, M. Mehta, Mathematical model for the formation of thin-film composite hollow fiber and tubular membranes by interfacial polymerization, J. Membr. Sci. 192 (2001) 41-54

[33] W. Fang, L. Shi, R. Wang, Interfacially polymerized composite nanofiltration hollow fiber membranes for low-pressure water softening, J. Membr. Sci. 430 (2013) 129-139.

[34] H. Futselaar, H. Schonewille, W. van der Meer, Direct capillary nanofiltration - a new high-grade purification concept, Desalination 145 (2002) 75-80.

[35] K. Wang, T. Chung, Fabrication of polybenzimidazole (PBI) nanofiltration hollow fiber membranes for removal of chromate, J. Membr. Sci. 281 (2006) 307-315.

[36] Y. Yang, X. Jian, D. Yang, S. Zhang, L. Zou, Poly(phthalazinone ether sulfone ketone) (PPESK) hollow fiber asymmetric nanofiltration membranes: preparation, morphologies and properties, J. Membr. Sci. 270 (2006) 1-12.

[37] F. Yang, S. Zhang, D. Yang, X. Jian, Preparation and characterization of polypiperazine amide/PPESK hollow fiber composite nanofiltration membrane, J. Membr. Sci. 301 (2007) 85-92.

[38] N. Bolong, A.F. Ismail, M.R. Salim, D. Rana, T. Matsuura, Development and characterization of novel charged surface modification macromolecule to polyethersulfone hollow fiber membrane with polyvinylpyrrolidone and water, J. Membr. Sci. 331 (2009) 40-49.

[39] S.P. Sun, K.Y. Wang, N. Peng, T.A. Hatton, T.-S. Chung, Novel polyamide-imide/ cellulose acetate dual-layer hollow fiber membranes for nanofiltration, J. Membr. Sci. 363 (2010) 232-242.

[40] S. Yu, Z. Chen, Q. Cheng, Z. Lü, M. Liu, C. Gao, Application of thin-film composite hollow fiber membrane to submerged nanofiltration of anionic dye aqueous solutions, Sep. Purif. Technol. 88 (2012) 121-129.

[41] S. Yu, Y. Zheng, Q. Zhou, S. Shuai, Z. Lü, C. Gao, Facile modification of polypropylene hollow fiber microfiltration membranes for nanofiltration, Desalination 298 (2012) 49-58.

[42] T. He, M. Frank, M.H.V. Mulder, M. Wessling, Preparation and characterization of nanofiltration membranes by coating polyethersulfone hollow fibers with sulfonated poly(ether ether ketone) (SPEEK), J. Membr. Sci. 307 (2008) 62-72.

[43] H. Kakida, Y. Chatani, H. Tadokoro, Crystal structure of poly(m-phenylene isophthalamide), J. Polym. Sci. Polym. Phys. Ed. 14 (1976) 427-435.

[44] P. Nimmanpipug, K. Tashiro, O. Rangsiman, Factors governing the three-dimensiona hydrogen-bond network structure of poly( $\mathrm{m}$-phenylene isophthalamide) and a series of its model compounds (4): similarity in local conformation and packing structure between a complicated three-arm model compound and the linear model compounds, J. Phys. Chem. B 110 (2006) 20858-20864.

[45] J. Huang, K. Zhang, The high flux poly (m-phenylene isophthalamide) nanofiltration membrane for dye purification and desalination, Desalination 282 (2011) 19-26.

[46] X.-L. Wang, T. Tsuru, S.-i. Nakao, S. Kimura, The electrostatic and steric-hindrance model for the transport of charged solutes through nanofiltration membranes, J. Membr. Sci. 135 (1997) 19-32.

[47] A.S. Michaels, Analysis and prediction of sieving curves for ultrafiltration membranes: a universal correlation? Sep. Sci. Technol. 15 (1980) 1305-1322.

[48] S. Singh, K.C. Khulbe, T. Matsuura, P. Ramamurthy, Membrane characterization by solute transport and atomic force microscopy, J. Membr. Sci. 142 (1998) 111-127.

[49] B. Torrestiana-Sanchez, R.I. Ortiz-Basurto, E. Brito-De La Fuente, Effect of nonsolvents on properties of spinning solutions and polyethersulfone hollow fiber ultrafiltration membranes, J. Membr. Sci. 152 (1999) 19-28.

[50] R.E. Kesting, Semipermeable membranes of cellulose acetate for desalination in the process of reverse osmosis. I. Lyotropic swelling of secondary cellulose acetate, J. Appl. Polym. Sci. 9 (1965) 663-688.

[51] D. Wang, K. Li, W.K. Teo, Polyethersulfone hollow fiber gas separation membranes prepared from NMP/alcohol solvent systems, J. Membr. Sci. 115 (1996) 85-108.

[52] C.M. Hansen, K. Skaarup, The three dimensional solubility parameter-key to paint component affinities III, J. Paint Technol. 39 (1967) 511

[53] B. Jung, J.K. Yoon, B. Kim, H.-W. Rhee, Effect of molecular weight of polymeric additives on formation, permeation properties and hypochlorite treatment of asymmetric polyacrylonitrile membranes, J. Membr. Sci. 243 (2004) 45-57.

[54] C. Barth, M.C. Gonçalves, A.T.N. Pires, J. Roeder, B.A. Wolf, Asymmetric polysulfone and polyethersulfone membranes: effects of thermodynamic conditions during formation on their performance, J. Membr. Sci. 169 (2000) 287-299.

[55] P. van de Witte, P.J. Dijkstra, J.W.A. van den Berg, J. Feijen, Phase separation processes in polymer solutions in relation to membrane formation, J. Membr. Sci. 117 (1996) $1-31$.

[56] S.K. Yong, J.K. Hyo, Y.K. Un, Asymmetric membrane formation via immersion precipitation method. I. Kinetic effect, J. Membr. Sci. 60 (1991) 219-232.

[57] S. Atchariyawut, C. Feng, R. Wang, R. Jiraratananon, D.T. Liang, Effect of membrane structure on mass-transfer in the membrane gas-liquid contacting process using microporous PVDF hollow fibers, J. Membr. Sci. 285 (2006) 272-281.

[58] A. Mansourizadeh, A.F. Ismail, Effect of LiCl concentration in the polymer dope on the structure and performance of hydrophobic PVDF hollow fiber membranes for $\mathrm{CO}_{2}$ absorption, Chem. Eng. J. 165 (2010) 980-988.

[59] N. Peng, T.-S. Chung, K.Y. Wang, Macrovoid evolution and critical factors to form macrovoid-free hollow fiber membranes, J. Membr. Sci. 318 (2008) 363-372. 
[60] J.-Y. Lai, F.-C. Lin, T.-T. Wu, D.-M. Wang, On the formation of macrovoids in PMMA membranes, J. Membr. Sci. 155 (1999) 31-43.

[61] Q. Yang, T.-S. Chung, M. Weber, Microscopic behavior of polyvinylpyrrolidone hydrophilizing agents on phase inversion polyethersulfone hollow fiber membranes for hemofiltration, J. Membr. Sci. 326 (2009) 322-331.

[62] J. Schaep, B. Van der Bruggen, C. Vandecasteele, D. Wilms, Influence of ion size and charge in nanofiltration, Sep. Purif. Technol. 14 (1998) 155-162.

[63] F.G. Donnan, Theory of membrane equilibria and membrane potentials in the presence of non-dialysing electrolytes. A contribution to physical-chemical physiology, J. Membr. Sci. 100 (1995) 45-55.
[64] H.D.W. Roesink, The influence of spinning conditions on the morphology of microporous capillary membranes(Ph.D. Thesis) University of Twente, The Netherland, 2015.

[65] M.-J. Han, S.-T. Nam, Thermodynamic and rheological variation in polysulfone solution by PVP and its effect in the preparation of phase inversion membrane, J. Membr. Sci. 202 (2002) 55-61.

[66] R. Naim, A.F. Ismail, A. Mansourizadeh, Effect of non-solvent additives on the structure and performance of PVDF hollow fiber membrane contactor for $\mathrm{CO}_{2}$ stripping, J. Membr. Sci. 423-424 (2012) 503-513. 